\title{
Intracellular localization of the BCL-2 family member BOK and functional implications
}

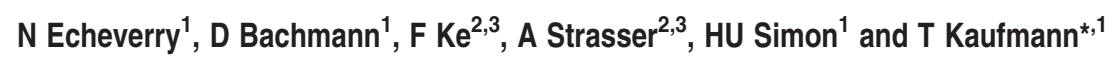

The pro-apoptotic BCL-2 family member BOK is widely expressed and resembles the multi-BH domain proteins BAX and BAK based on its amino acid sequence. The genomic region encoding BOK was reported to be frequently deleted in human cancer and it has therefore been hypothesized that BOK functions as a tumor suppressor. However, little is known about the molecular functions of BOK. We show that enforced expression of BOK activates the intrinsic (mitochondrial) apoptotic pathway in BAX/ BAK-proficient cells but fails to kill cells lacking both BAX and BAK or sensitize them to cytotoxic insults. Interestingly, major portions of endogenous BOK are localized to and partially inserted into the membranes of the Golgi apparatus as well as the endoplasmic reticulum (ER) and associated membranes. The C-terminal transmembrane domain of BOK thereby constitutes a 'tail-anchor' specific for targeting to the Golgi and ER. Overexpression of full-length BOK causes early fragmentation of ER and Golgi compartments. A role for BOK on the Golgi apparatus and the ER is supported by an abnormal response of Bok-deficient cells to the Golgi/ER stressor brefeldin A. Based on these results, we propose that major functions of BOK are exerted at the Golgi and ER membranes and that BOK induces apoptosis in a manner dependent on BAX and BAK.

Cell Death and Differentiation (2013) 20, 785-799; doi:10.1038/cdd.2013.10; published online 22 February 2013

The intrinsic (mitochondrial) apoptotic pathway is stringently controlled by the BCL-2 protein family, which is divided into three groups based on the ability to induce or antagonize apoptosis and the presence of up to four short conserved domains, termed BCL-2 homology domains (BH1-BH4). ${ }^{1}$ The members of the pro-survival subgroup (BCL-2, MCL-1, BFL-1/ $A 1, B C L-X_{L}$ and $B C L-W$ ) inhibit apoptosis and contain all four $\mathrm{BH}$ domains $(\mathrm{BH} 1-\mathrm{BH} 4){ }^{2}$ The pro-apoptotic members are divided into two subgroups, the multi-BH domain-containing BAX-like family (BAX, BAK and BOK), and the BH3-only proteins (BIM, BID, NOXA, BAD, PUMA, BIK, HRK and $\mathrm{BMF}) .^{3}$ The latter contain only a $\mathrm{BH} 3$ domain, which is essential for apoptosis initiation upon activation in response to apoptotic stimuli. ${ }^{4}$ By a series of complex and still controversially discussed protein-protein interactions, activated $\mathrm{BH} 3-$ only proteins transmit the apoptotic signal to BAX and BAK, which are essential for mitochondrial outer membrane permeabilization (MOMP) ${ }^{5,6}$ MOMP is commonly seen as the point-of-no-return in the intrinsic apoptotic pathway; it unleashes the activation of apoptotic caspases that are responsible for the demolition of many vital cellular substrates and consequently the morphological changes observed during apoptosis. ${ }^{7,8}$

Most BCL-2 family members are tail-anchored to the mitochondrial outer membrane via a C-terminal $\alpha$-helical transmembrane domain (TMD) that serves both as a targeting and anchoring device. ${ }^{2,9}$ However, several members, including BCL-2, BAX and BAK, are also present on other organelles, most notably the endoplasmic reticulum (ER), where they have been reported to be involved in the regulation of calcium homeostasis, autophagy and ER stress responses. ${ }^{2,10-15}$

BOK (BCL-2-related ovarian killer) was identified in a yeast two-hybrid screen using MCL-1 as bait and was shown to selectively interact with MCL-1 and BFL-1/A1 but not with BCL-2 or BCL- $X_{L} \cdot{ }^{16,17}$ Among the BCL-2 family members, BOK shows the highest evolutionary conservation. ${ }^{18,19}$ Bok expression was first reported to be restricted to reproductive tissues. ${ }^{16}$ However, we have recently shown that BOK can be detected in most tissues, albeit in several at only relatively low levels. ${ }^{20}$ The BOK protein was found to localize to the mitochondria, the ER as well as to the nucleus. ${ }^{18,21,22}$

Several studies, largely relying on protein overexpression, have shown that BOK can induce cell death; however, the exact mechanisms are poorly understood and may involve both caspase-dependent and -independent pathways. ${ }^{16,17,23}$ Based on the high sequence similarity of BOK with BAX and BAK (particularly in the $\mathrm{BH} 1-3$ domains), it has been assumed that BOK might function similar to BAX/BAK. ${ }^{16,17,20-22,24}$ However, the high resistance of cells lacking both BAX and BAK towards possibly all intrinsic apoptotic stimuli, ${ }^{25,26}$ together with detectable BOK levels in those cells, raises

\footnotetext{
${ }^{1}$ Institute of Pharmacology, University of Bern, Bern, Switzerland; ${ }^{2}$ The Walter and Eliza Hall Institute of Medical Research, Melbourne, Australia and ${ }^{3}$ Department of Medical Biology, The University of Melbourne, Melbourne, Australia

*Corresponding author: T Kaufmann, Institute of Pharmacology, University of Bern, Friedbuehlstrasse 49, Bern CH-3010, Switzerland. Tel: + 0041316323289 ; Fax: + 00413163249 92; E-mail: thomas.kaufmann@pki.unibe.ch

Keywords: apoptosis; BOK; BAX/BAK; tail-anchor; Golgi; ER

Abbreviations: 4-OHT, 4-hydroxytamoxifen; BFA, brefeldin A; BH, BCL-2 homology; BOK, BCL-2-related ovarian killer; BIM, BCL-2-interacting mediator of cell death; ER, endoplasmic reticulum; GRP78 (BiP), glucose-regulated protein 78 (binding protein); GM130, Golgi matrix 130; MAM, mitochondria-associated membrane; IRE1 $\alpha$, inositol requiring kinase and endonuclease 1 alpha; MCL-1, myeloid-cell leukemia sequence 1; MOMP, mitochondrial outer membrane permeabilization; TMD, transmembrane domain

Received 20.8.12; revised 22.12.12; accepted 11.1.13; Edited by C Borner; published online 22.2.13
} 
the question whether BOK can substitute for the function of BAX and BAK.

Using gene targeting in ES cells, we have shown that mice develop normally in the absence of Bok and that young adult Bok $^{-/-}$mice show no obvious abnormalities. Furthermore, $\mathrm{Bok}^{-/-}$hematopoietic cells responded normally to diverse classical apoptotic stimuli, such as cytokine deprivation or $\gamma$-irradiation. ${ }^{20}$ Interestingly, Beroukhim et al. ${ }^{27}$ have recently reported that the $B O K$ gene is localized in a region of the genome that is frequently deleted in human cancer. It is therefore possible that BOK acts as a tumor suppressor. However, the loss of Bok did not accelerate the development of pre-B/B-cell lymphoma in the $E \mu-M y c$ transgenic mouse model. ${ }^{20}$ This result may indicate that Bok may have a role in tumor suppression in cells outside the lymphoid system, consistent with the observation that Bok expression in lymphocytes is low. ${ }^{20}$

In this study, we investigated the subcellular localization of overexpressed and endogenous BOK and its potential to kill cells in the presence or absence of BAX/BAK. We found that substantial portions of BOK protein are present on the Golgi and ER membranes. Overexpressed BOK was found to cause early fragmentation of Golgi and ER compartments upstream of caspase activation. Interestingly, BOK failed to kill $\mathrm{Bax}^{-1-} \mathrm{Bak}^{-/-}$doubly deficient cells and high BOK levels could not substitute for the combined loss of BAX and BAK in inducing apoptosis in response to stress stimuli. Finally, BOKdeficient cells responded abnormally to brefeldin $A$, a drug that has an impact on the Golgi/ER, supporting a role for BOK within these subcellular compartments. Taken together, these results indicate that $\mathrm{BOK}$ has important roles on the membranes of the Golgi and ER and activates the intrinsic apoptotic pathway in a manner dependent on BAX and BAK.

\section{Results}

BOK-induced apoptosis is largely BAX/BAK-dependent. We have recently shown that BOK is widely expressed in the mouse (Ke et $\mathrm{al}^{20}$ and Supplementary Figure S1), therefore, perhaps indicating that based on its resemblance to BAX and BAK it may have a role in apoptosis in many cell types. However, mice lacking both Bax and Bak present with severe phenotypic abnormalities in diverse tissues, such as epithelial, neuronal and hematopoietic ones. Moreover, cells derived from these mice are highly resistant towards possibly all intrinsic apoptotic stimuli, ${ }^{25,28}$ even though they do express endogenous BOK. This may indicate that BOK does not exert a major role overlapping with those of $B A X$ and BAK. To investigate the function of BOK further, and given that overexpression of $\mathrm{BOK}$ was previously reported to induce apoptosis, ${ }^{16-18,21-23}$ we examined whether BOKinduced apoptosis depends on the presence of BAX/BAK.

Using an inducible expression system ${ }^{29}$ or transient transfection, we first confirmed that BOK overexpression kills several nontransformed and transformed cells. As shown in Figure 1, SV40 large T antigen-immortalized mouse embryo fibroblasts (SV40 MEF) died upon induction of BOK, exhibiting classical features of apoptosis, including rounding and detachment, plasma membrane blebbing, phosphatidylserine exposure, effector caspase activation and increased subG1
DNA content. Induction of EGFP expression did not kill these cells and 4-hydroxytamoxifen did not exert cytotoxicity. This shows that BOK overexpression can specifically kill these cells (Figure $1 \mathrm{~b}$ and Supplementary Figure S2). Overexpressed BOK induced cytochrome $c$ release and caspase- 9 activation preceding caspase-3 processing (Figure 1e-h). Similarly, growth factor-dependent murine myeloid progenitors (FDM), the IL-3-dependent pro-B cell line $\mathrm{BaF} / 3$, human Jurkat T-cell leukemia as well as HeLa cervical cancer-derived cells were killed in response to BOK overexpression (Figure 2d, Supplementary Figure S3). This cell death could be inhibited by addition of the pan-caspase inhibitor Q-VD-OPh (Figure 1a, Supplementary Figure S3a and S3e). Importantly, BOKinduced cytochrome $c$ release occurred upstream of caspase activation (Figure 1f). This indicates that BOK-induced cell killing proceeds via the intrinsic apoptotic pathway. BOKinduced killing was independent of the presence of endogenous BOK (Supplementary Figure S3f) and BOK overexpression killed MCL-1-deficient MEF significantly faster than WT cells, further supporting the notion that BOK activates the intrinsic apoptotic pathway (Figure 1a).

To investigate whether BOK-induced apoptosis was dependent on BAX and BAK, we overexpressed BOK in $\mathrm{Bax}^{-1-} \mathrm{Bak}^{-1-}$ MEF and FDM. Although BOK overexpression could efficiently kill WT MEF and FDM, this largely (MEF) or completely (FDM) failed to kill cells lacking both BAX and BAK (Figure $2 a, b, d$ ). In contrast, MEF or FDM lacking only $B A X$ or BAK, respectively, were normally sensitive to BOKinduced killing (not shown). Importantly, BOK overexpression also failed to sensitize $\mathrm{Bax}^{-/-} \mathrm{Bak}^{-/-}$MEF and FDM to classical apoptotic stimuli, including treatment with etoposide or staurosporine (Figure $2 \mathrm{c}$ and $\mathrm{d}$ ).

We next examined which protein-protein interactions are critical for BOK overexpression-induced apoptosis. The D83G mutation in BAK was shown to prevent homodimerization/oligomerization and consequently abrogated its ability to kill $\mathrm{Bax}^{-1-} \mathrm{Bak}^{-1-} \mathrm{MEF}{ }^{30}$ Intriguingly, BAK(D83G) was still capable of killing HEK293T cells, ${ }^{30}$ as was the corresponding $\mathrm{BAX}(\mathrm{D} 68 \mathrm{~A})$ mutant, $^{31}$ indicating that these mutants can activate endogenous BAX/BAK. We found that FLAG(WT)BOK co-immunoprecipitated HA-(WT)BOK, but this interaction was disrupted by a point mutation of the conserved aspartate $^{76}$ residue within its $\mathrm{BH} 3$ domain (Figure $2 \mathrm{e}$ ). Interestingly, BOK(D76A) retained its full ability to kill WT and $\mathrm{Bok}^{-1-}$ cells, indicating that BOK may trigger apoptosis as a monomer (Figure 2f). No significant interaction was found by co-immunoprecipitation analysis between WT BOK and pro- or anti-apoptotic BCL-2 family members (Figure 3). Collectively, these results show that BOK overexpression induces apoptosis in BAX/BAK-proficient but not in BAX/BAK DKO cells, indicating that BOK may act upstream of BAX and BAK in the intrinsic apoptotic pathway.

Overexpressed BOK localizes to the ER and Golgi apparatus. When we analyzed the subcellular localization of overexpressed FLAG- or EGFP-tagged BOK by confocal microscopy, we found that BOK only partially colocalized with mitochondrial markers but was also found on other intracellular membranes (Figures $4 \mathrm{a}$ and $5 \mathrm{~b}$ ). Using staining for organelle-specific markers, we found that BOK was 
a
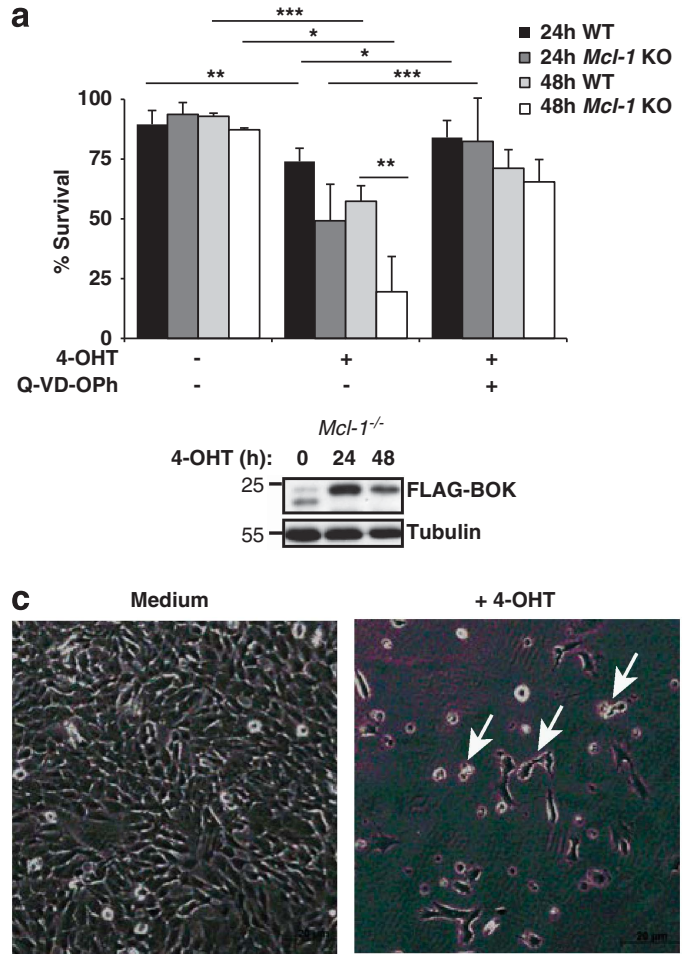

e
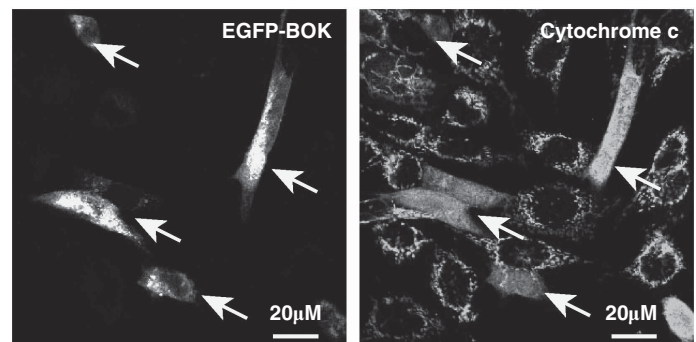

h

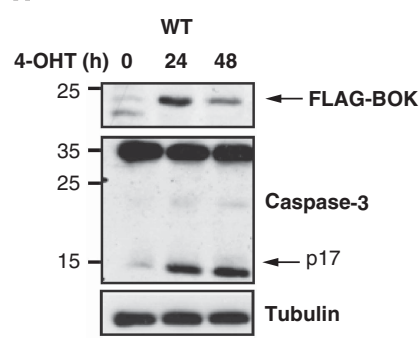

b

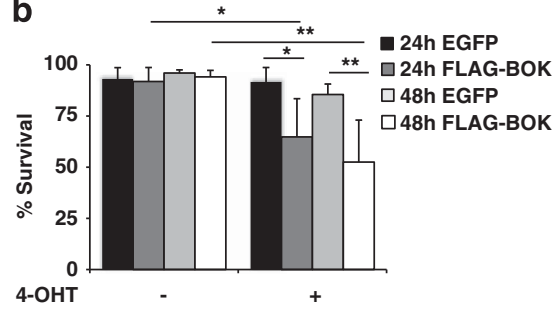

d Medium
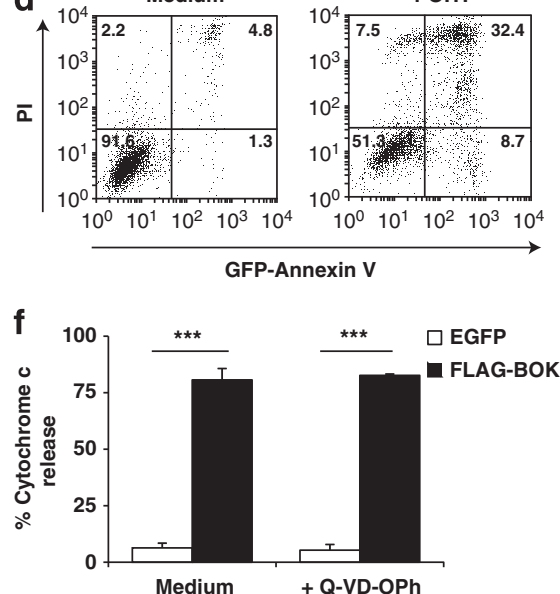

g biotin-X-VAD-fmk pulldown

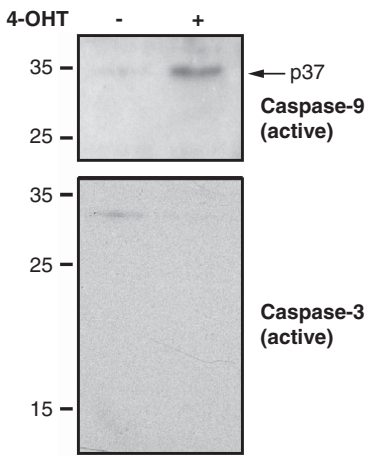

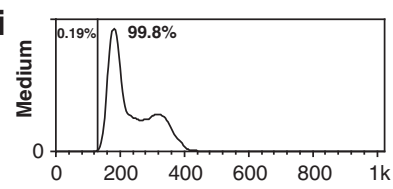

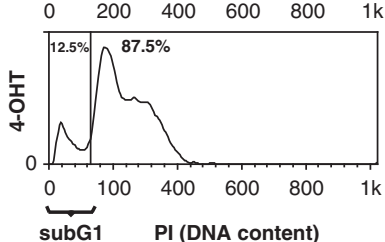

Figure 1 Overexpressed BOK activates the intrinsic apoptotic pathway in SV40-immortalized MEF. (a) SV40-immortalized WT and Mcl-1 ${ }^{-/-}$MEF/5XUAS-FLAG-BOK cells were treated as indicated with 4-OHT $(0.1 \mu \mathrm{M})$ and Q-VD-OPh $(25 \mu \mathrm{M})$ for 24 or $48 \mathrm{~h}$ and viability assessed by GFP-Annexin V/PI staining and flow cytometry. Data are presented as means \pm S.D. from three independent experiments. Induction of FLAG-BOK in SV40-immortalized WT (see $\mathrm{h}$ ) and $\mathrm{Mcl}-1^{-1-}$ MEF was controlled by Western blotting. (b) SV40-immortalized WT MEF/5xUAS-FLAG-BOK and WT MEF/5xUAS-EGFP cells were treated with 4-OHT $(0.1 \mu \mathrm{M})$ for 24 or $48 \mathrm{~h}$ and viability assessed by PI staining and flow cytometry. Data represent means \pm S.D. from 6 (FLAG-BOK) and 5 (EGFP) independent experiments, respectively. (c) Wide-field micrographs of WT $\mathrm{MEF} / 5 \mathrm{xUAS}-\mathrm{FLAG}-\mathrm{BOK}$ cells induced for $48 \mathrm{~h}$ with $0.1 \mu \mathrm{M} 4-\mathrm{OHT}$. White arrows indicate apoptotic cells characterized by plasma membrane blebbing, rounding and detachment. (d) Representative dot plots $(n \geq 6)$ of GFP-Annexin V/PI staining of MEF/5xUAS-FLAG-BOK cells with or without FLAG-BOK induction for $48 \mathrm{~h}$. (e) Confocal micrographs of WT MEF transiently transfected with EGFP-BOK for $9 \mathrm{~h}$ and immunostained with an antibody against cytochrome c. (f) WT MEF were transfected with expression constructs for EGFP or FLAG-BOK, in the absence or presence of $20 \mu \mathrm{M}$ Q-VD-OPh, for $9 \mathrm{~h}$ and percentages of EGFP- or FLAG-BOK-positive cells with released cytochrome $\mathrm{c}$ determined by counting 100 cells for each condition. Data represent means \pm S.D. of three independent experiments. (g) WT MEF/5xUAS-FLAG-BOK cells were left untreated or treated with $0.1 \mu \mathrm{M} 4-\mathrm{OHT}$ for $14 \mathrm{~h}$. Active caspases were covalently labeled with biotinylated X-VAD-fmk, pulled down with streptavidin-sepharose beads and Western blots probed for caspase-9 and caspase-3. Whereas active caspase-9 was pulled down, no signal for active caspase-3 could be detected at this specific time point. (h) WT MEF/5xUAS-FLAG-BOK cells were treated with 4-OHT $(0.1 \mu \mathrm{M})$ for the indicated times and total protein lysates analyzed by Western blotting using anti-BOK and anti-caspase-3 antibodies. (i) Representative histograms $(n \geqslant 3)$ showing DNA content of WT MEF/5XUAS-FLAG-BOK with or without FLAG-BOK induction ( $t=48 \mathrm{~h})$. The cell population with fragmented genomic DNA is indicated as subG1. Significance values were determined by paired Student's $t$-test $\left({ }^{* * *} P<0.005 ;{ }^{* \star} P<0.01 ;{ }^{*} P<0.05\right)$ 
prominently associated with the membranes of the endoplasmic reticulum (ER) and its associated nuclear outer membrane (colocalization with calnexin) as well as with the Golgi apparatus (colocalization with cis-Golgi protein GM130 and trans-/medial-Golgi protein GalNAc-T2) (Figure 4a). In addition, overexpressed BOK showed vesicular localization patterns, particularly at later time points and upon blocking of apoptosis with Q-VD-OPh. This vesicular BOK partially colocalized with the early and recycle endosome markers RAB4 and RAB11, respectively, the late endosome marker RAB5a and was found in LysoTracker-positive vesicles (acidic organelle marker) (Figure $4 \mathrm{~b}$ and Supplementary a

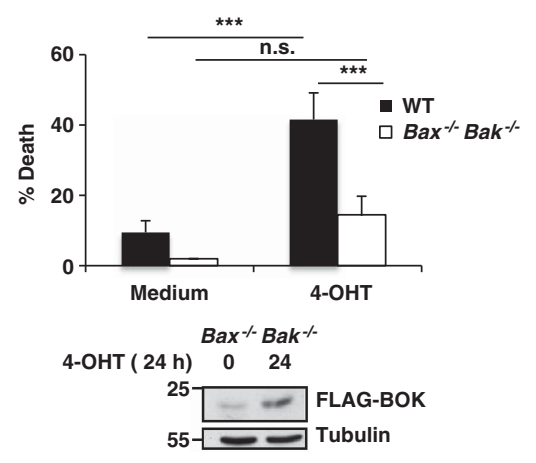

b

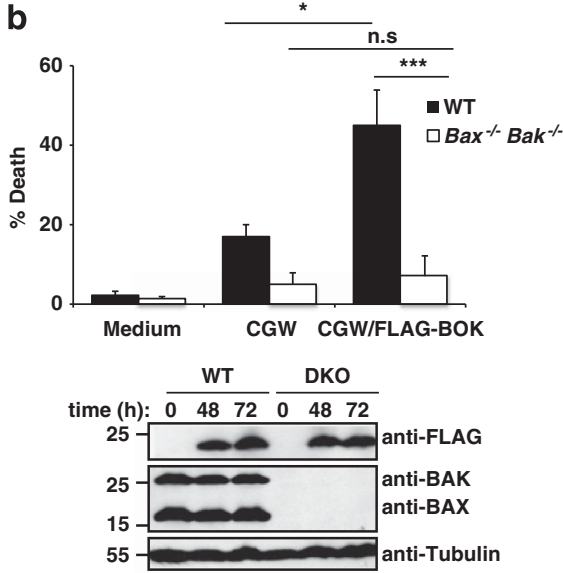

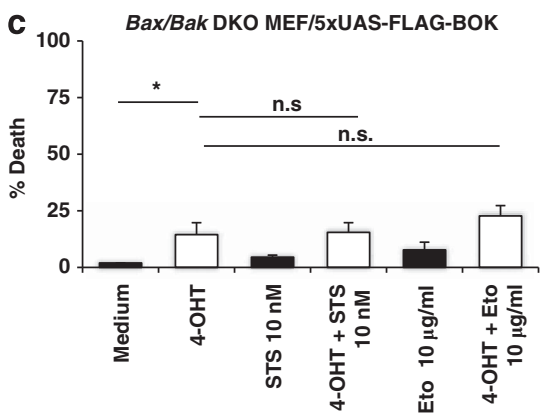
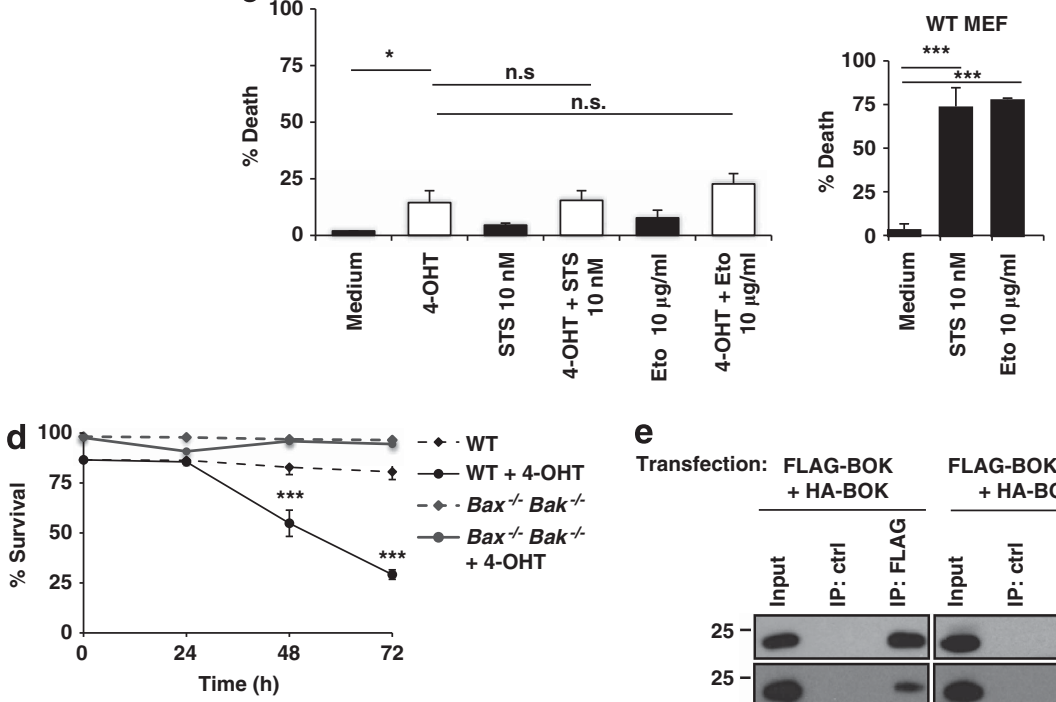

e

Transfection: FLAG-BOK
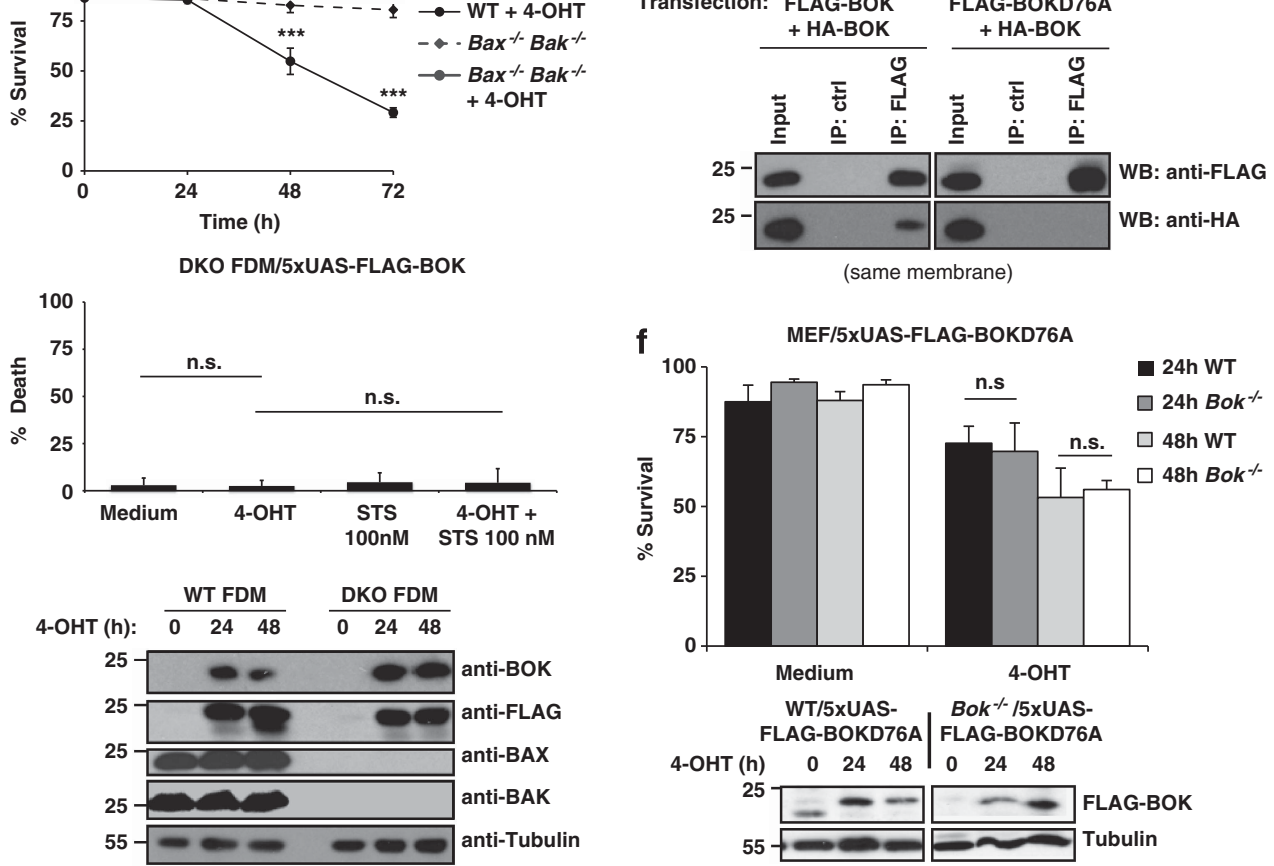
Figure S4). Interestingly, cells overexpressing BOK showed readily detectable changes in ER and Golgi morphology. The ER appeared swollen and fragmented (punctuated pattern) and the Golgi apparatus displayed weakened GM130 staining at early time points and a fragmented pattern at later time points. These alterations clearly depended on overexpression of full-length BOK, because these organelles were not affected in cells overexpressing EGFP fused to the TMD of BOK only (Figure 5). BOK-induced disruption of Golgi and ER structures occurred upstream of caspase activation as it was also seen in the presence of Q-VD-OPh (Figure 4c). Taken together, these results show that major portions of overexpressed BOK are found on the
ER-, Golgi- and associated membranes and BOK overexpression rapidly leads to the fragmentation of these organelles in a caspase-independent manner. BOK may thus have a role in the dismantling of these organelles during apoptosis.

The TMD of BOK is necessary and sufficient for Golgi and ER targeting. The putative TMD of BOK atypically contains two positively charged amino acids, arginine ${ }^{200}$ and lysine $^{203}$, weakening its hydrophobicity (Figure 5a). Similar to $\mathrm{BCL}-2$, the net positive charge at the C-terminal end of BOK is $\leqslant+1$, whereas others and we have shown that a net positive charge of $\geqslant+2$ is required for specific mitochondrial targeting. $2,11,32,33$ To test whether the TMD of BOK is a
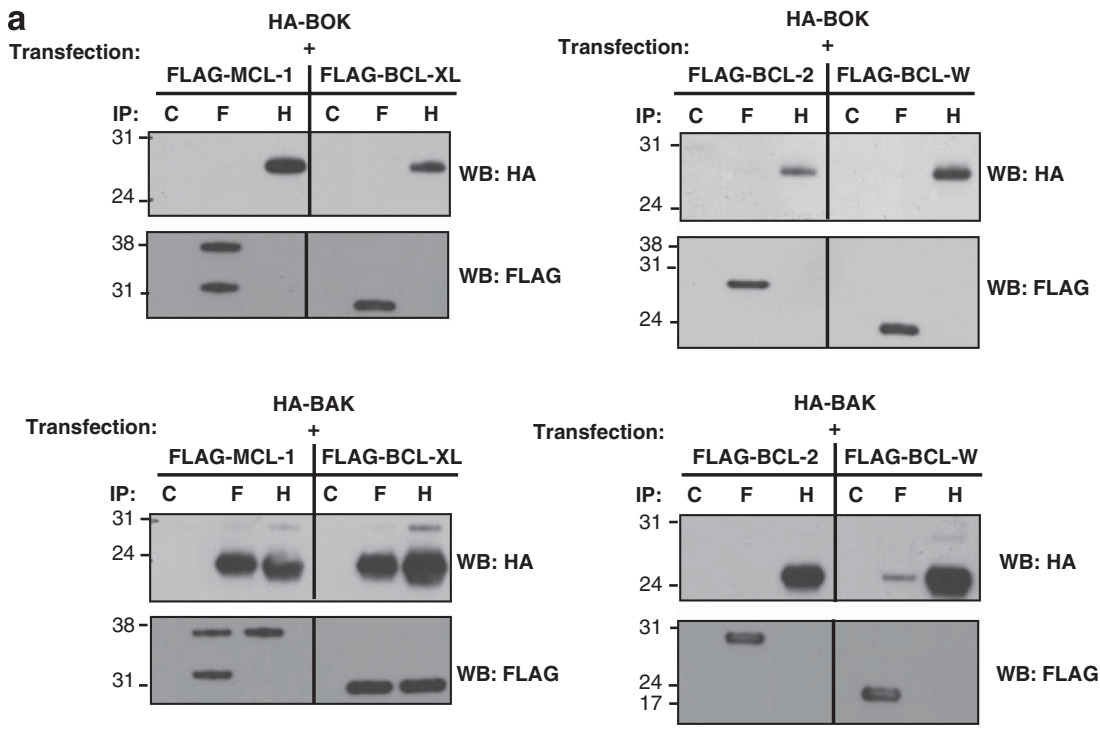

b

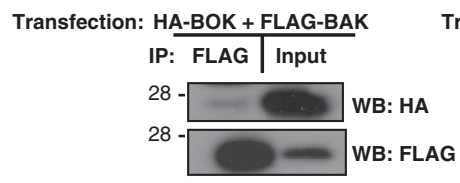

Transfection: HA-BOK + FLAG-BAX

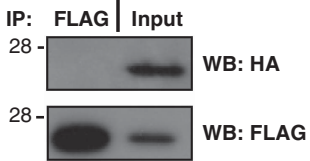

Figure 3 BOK does not co-immunoprecipitate with other BCL-2 family members. (a) HA-BOK or HA-BAK were transiently co-expressed with FLAG-tagged MCL-1, BCL$X_{L}, B C L-2$ or BCL-W in HEK 293T cells. Immunoprecipitates (C: protein G sepharose beads only; F: anti-FLAG; H: anti-HA) were probed by Western blotting with anti-FLAG and anti-HA antibodies. (b) HA-BOK was transiently co-transfected with FLAG-BAX or FLAG-BAK. Anti-FLAG immunoprecipitates were probed by Western blot using anti-HA and anti-FLAG antibodies

Figure 2 BOK-induced apoptosis is largely BAX/BAK-dependent. (a) FLAG-BOK was induced in SV40-immortalized WT and Bax ${ }^{-1-}$ Bak $^{-1-}$ MEF/5XUAS-FLAG-BOK cells by addition of $0.1 \mu \mathrm{M} 4-\mathrm{OHT}$. Cell death was determined after $48 \mathrm{~h}$ by flow cytometric analysis (after staining with GFP-Annexin V and PI). Data are presented as means \pm S.D. from greater than three independent experiments. (b) WT and $\mathrm{Bax}^{-/} \mathrm{Bak}^{-/-}$SV40 MEF were transduced with CAD-G-Whiz empty vector (CGW) or CGW/FLAGBOK for $40 \mathrm{~h}$ and apoptosis of EGFP-positive cells measured by flow cytometry (Cherry-Annexin V-positive cells). Data are presented as means \pm S.D. from three independent experiments. FLAG-BOK expression and correct genotypes were verified by Western blotting, using antibodies to BOK, BAX and BAK. (c) FLAG-BOK was induced in $\mathrm{Bax}^{-1-} \mathrm{Bak}^{-1-} \mathrm{MEF} / 5 \mathrm{xUAS}-\mathrm{FLAG}-\mathrm{BOK}$ cells for $24 \mathrm{~h}$, followed by treatment with $10 \mathrm{nM}$ staurosporine or $10 \mu \mathrm{g} / \mathrm{ml}$ etoposide for an additional $24 \mathrm{~h}$. Cell death was quantified as described in (a). WT SV40 MEF treated with the same concentration of drugs for $24 \mathrm{~h}$ are shown as a control. Data represent means \pm S.D. from three independent experiments. (d) Survival of WT and $\mathrm{Bax}^{-1-} \mathrm{Bak}^{-1-} \mathrm{FDM} / 5 \mathrm{XUAS}-\mathrm{FLAG}-\mathrm{BOK}$ cells with or without induction of FLAG-BOK expression (upper panel). Surviving cells were determined by flow cytometry and data represent GFP-Annexin V/PI double-negative cells. Data represent means \pm S.D. from three independent experiments. Lower panel: FLAG-BOK was induced for $8 \mathrm{~h}$ in $\mathrm{Bax}^{-1-} \mathrm{Bak}^{-1-} \mathrm{FDM} / 5 \mathrm{xUAS}-\mathrm{FLAG}-\mathrm{BOK}$ cells, followed by treatment with $100 \mathrm{nM}$ staurosporine for an additional $24 \mathrm{~h}$. Data represent means \pm S.D. from greater than three independent experiments. FLAG-BOK expression and correct genotypes were verified by Western blotting, using antibodies to FLAG, BOK (RabMab BOK-1-5), BAX and BAK. (e) Co-immunoprecipitation assay in HEK 293T cells transiently co-transfected for 14h with HA-BOK/pcDNA3 and FLAG-BOK/pcDNA3 or FLAG-BOK(D76A)/pcDNA3. Anti-FLAG and non-specific mouse IgG1 (isotype control) immunoprecipitates were probed by Western blotting using HA- and FLAG-specific antibodies. (f) Viability of WT and Bok ${ }^{-1}-$ SV40 MEF upon induction of FLAG-BOK(D76A) was determined by GFP-Annexin V/ PI negativity by flow cytometry. Induction of FLAG-BOK(D76A) was controlled by Western blotting using anti-BOK antibody. Data are presented as means \pm S.D. of greater than three independent experiments. Significance was determined by Student's $t$-test ${ }^{\star \star *} P<0.005,{ }^{\star \star} P<0.01$ and ${ }^{\star} P<0.05$; n.s.: not significant) 

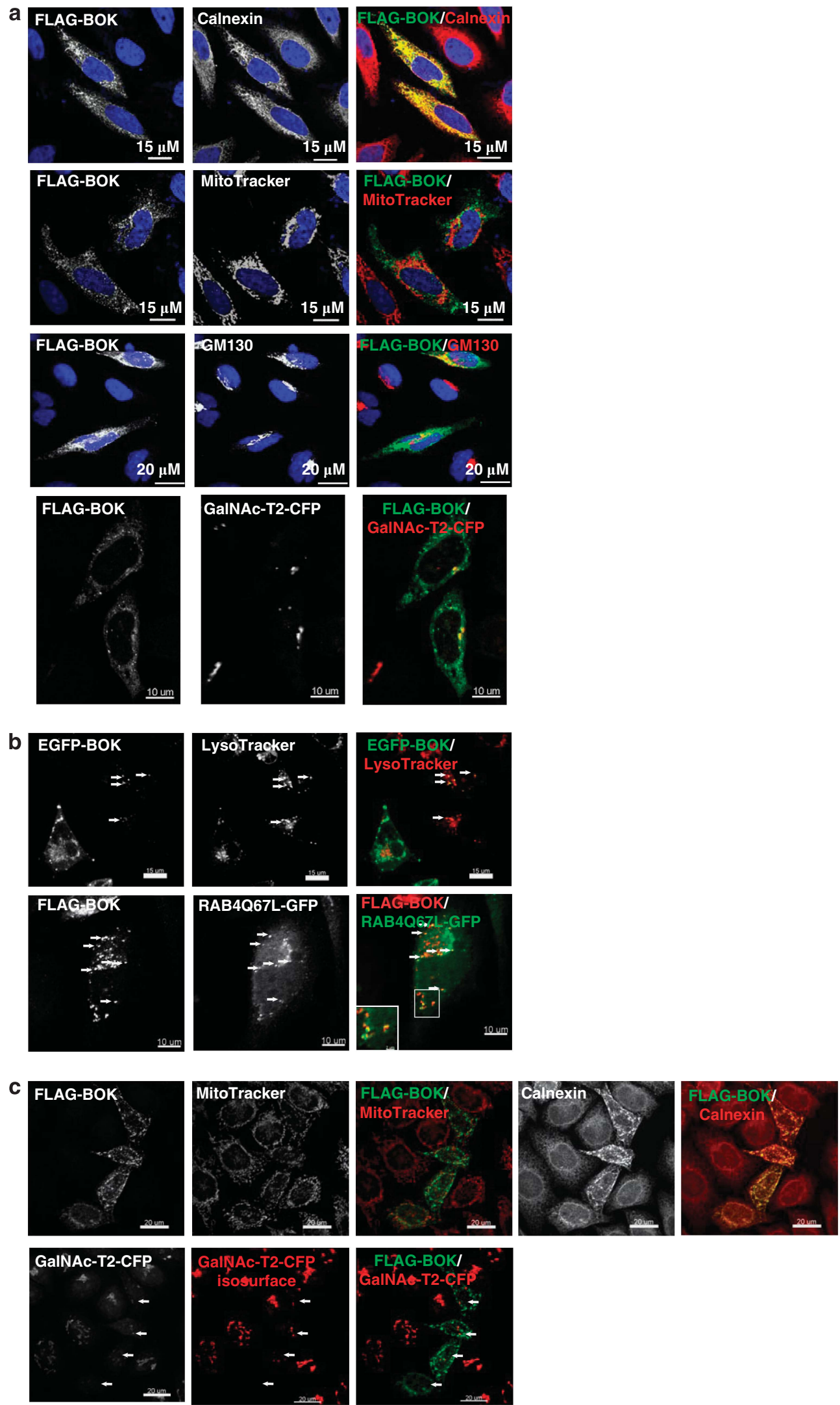
functional tail-anchor, we generated a TMD-deletion mutant. Overexpressed EGFP-BOK $\triangle T$ TMD lacked organelle-targeting potential and, accordingly, was diffusely distributed in the cytosol and nucleus (Figure 5b). To test whether the TMD of BOK is sufficient for organelle targeting, we fused the 35 (or 27, not shown) C-terminal amino acids of BOK, encompassing its TMD plus flanking residues, to the $\mathrm{C}$-terminus of EGFP. EGFP-TMD(BOK) efficiently colocalized with Golgiand ER markers but not clearly with mitochondrial markers (Figure $5 \mathrm{c}$ and $\mathrm{d}$ ). These results show that the TMD of BOK is both necessary and sufficient for intracellular targeting to ER- and Golgi membranes.

Subcellular localization of endogenous BOK. We next analyzed the subcellular localization of endogenous BOK in MEF by confocal microscopy. This confirmed a strong association of BOK with the Golgi apparatus and the ER, whereas endogenous BOK only partially colocalized with mitochondrial markers (Figure 6). The localization of endogenous BOK on the ER resembled the pattern seen for BCL-2, which is known to reside on the $E R /$ nuclear outer membrane. ${ }^{11,34,35}$ However, in contrast to BOK, BCL-2 showed no Golgi-specific staining. To further investigate the localization of BOK on the Golgi apparatus, we treated MEF with brefeldin A (BFA), a drug that leads to Golgi fragmentation and is widely used to investigate Golgi apparatus dynamics. ${ }^{36}$ BFA-treated MEF showed a rapid fragmentation of the Golgi into GM130-positive vesicular structures largely staining positive for BOK (Figure 6d).

Subcellular fractionation of MEF followed by Western blotting revealed that a major portion of both overexpressed and endogenous BOK was present in the microsomal fraction positive for the Golgi marker GM130. BOK was further found in calnexin-positive ER-derived heavy membranes and in mitochondria-enriched fractions but not in cytosolic fractions (Figure 7a and b). In comparison, endogenous BAX and BAK, both of which were reported to also localize to ER membranes, ${ }^{37,38}$ were found at only low levels in the microsomal fraction. The subcellular distribution of endogenous BOK was independently confirmed in freshly isolated mouse hepatocytes, a primary cell type that expresses relatively high amounts of BOK (Figure 7c).

To determine whether organelle-targeted BOK was integrally inserted into the membranes, we treated membrane fractions isolated from MEF and primary hepatocytes with alkaline solution. ${ }^{11}$ Both endogenous and overexpressed BOK were fully inserted into heavy membranes, whereas a portion of BOK present on microsomes was only loosely attached (Figure $7 d$ and e). Trypsin treatment of isolated membrane fractions completely degraded endogenous BOK protein, demonstrating that the epitope-carrying $\mathrm{N}$-terminus of BOK faces the cytosol (Figure 7f). This indicates that, similar to other BCL-2 family members, BOK may be inserted into organelle membranes with the bulk of the protein facing the cytosol. Furthermore, and in contrast to BAK, BAX or BCL-2, we found a significant portion of BOK in purified nuclear fractions (Figure $7 \mathrm{~g}$ ). Taken together, our microscopic and biochemical studies provide evidence that major portions of BOK localize to intracellular membranes other than the mitochondrial, in particular Golgi- and ER membranes.

Bok-deficient cells respond abnormally to the Golgi/ ER-stressing drug brefeldin A. As BOK was found on Golgi/ER membranes, we examined the response of WT and Bok-deficient cells to BFA, a drug that results in the collapse of the Golgi complex into the ER, leading to ER stress and apoptosis. ${ }^{36,39}$ Although BFA-induced Golgi fragmentation occurred normally in the absence of BOK (Supplementary Figure S5), BFA-treated Bok ${ }^{-/}$cells (MEF, mast cells and myeloid progenitors) responded with an abnormal ER stress response (Figure 8). Interestingly, BFA-treated cells died slightly but significantly faster in the absence of BOK. The same cells responded normally to other apoptotic stresses (e.g. etoposide, staurosporine), even though a minor but significant acceleration in cell death was also observed for tunicamycin-treated $\mathrm{Bok}^{-/-}$mast cells (Supplementary Figure S6). Western blot analysis revealed a disturbed ER stress-response in $\mathrm{Bok}^{-/-} \mathrm{MEF}$, as shown by defective upregulation of IRE $1 \alpha$ and GRP78, and increase in active C-Jun-N-terminal kinase (JNK), the BH3-only protein BIM, active caspase- 3 and cleaved PARP. In conclusion, we observed an abnormal ER stress response after BFA treatment in the absence of BOK, supporting a role for BOK within the Golgi and ER compartments.

\section{Discussion}

We show, in accordance with previous reports, ${ }^{16}$ that BOK overexpression can kill several cell lines tested. BOK activates the BCL-2-regulated (intrinsic) apoptotic pathway, as shown by characteristic morphological changes, cytochrome $c$ release upstream of caspase-activation as well as caspase- 9 and subsequent caspase-3 activation. Involvement of the BCL-2-regulated apoptotic pathway is supported by our observation that MEF lacking MCL-1 were significantly more sensitive to BOK-induced killing than WT controls. However, even though BOK shows amino-acid sequence similarities to $\mathrm{BAX}$ and $\mathrm{BAK}$, it is not known whether $\mathrm{BOK}$ is a

Figure 4 Overexpressed BOK mainly localizes to membranes of the endoplasmic reticulum, Golgi apparatus and associated membranes. (a) Representative confocal scanning micrographs of HeLa cells transiently transfected with FLAG-BOK/pcDNA3 for $18 \mathrm{~h}$ and stained with organelle-specific antibodies against calnexin (endoplasmic reticulum) or GM130 (Golgi matrix), MitoTracker Deep Red 633 (mitochondria), GalNAc-T2-CFP (trans and medial Golgi) and Hoechst 33342 (nuclei). (b) HeLa cells were transfected with pEGFP-BOK for $8 \mathrm{~h}$. Images were taken at real time. EGFP-BOK is found in vesicular patterns and partially colocalizes with the acidic organelle marker LysoTracker, as indicated by white arrows. FLAG-BOK and GFP-RAB4Q67L-GFP (constitutive active mutant, endosomal marker) were co-expressed in HeLa cells for $22 \mathrm{~h}$. Partial colocalization is indicated by white arrows and in the magnified inlet. (c) HeLa cells stably expressing GaLNAc-T2-CFP (specific marker for trans and medial Golgi ${ }^{52}$ ) were transfected with FLAG-BOK/pcDNA3 for $21 \mathrm{~h}$ in the presence of $25 \mu \mathrm{M}$ Q-VD-OPh. Cells were stained with antibodies to calnexin and MitoTracker Deep Red 633. Forty Z-stacks were acquired and GaLNaC-T2-CFP channel iso-surface 3D Golgi reconstruction was performed using the IMARIS software. Cells expressing FLAG-BOK (white arrows) show weakened GalNAc-T2-CFP signal intensity, correlating with increased Golgi dissociation and fragmentation compared with non-transfected cells 
a BCL-X GQERFNR WFLTGMTVAGVVLGSLFSRK

BCL-2 FSWKSLKTLLSLALVVGACITLGAYLGH $K$

BAX LSYFGTPTWQTVTIFVAGVLTASLTIW KKMG

BAX AALNLRRDPILTVMVIFGVVLGQFVVH RFFRS

BOK VVSTDPGFRSHWLVATLCSFGRFLKAAFFLLLPER

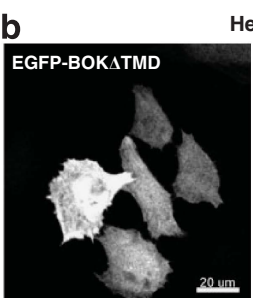

HeLa
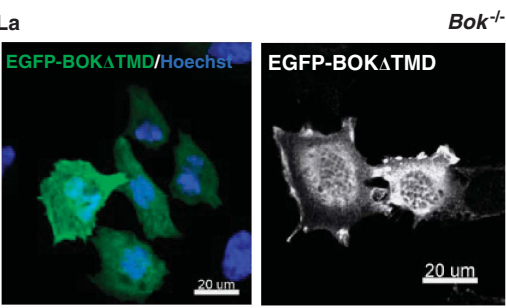

$\mathrm{Bok}^{-/-}$MEF
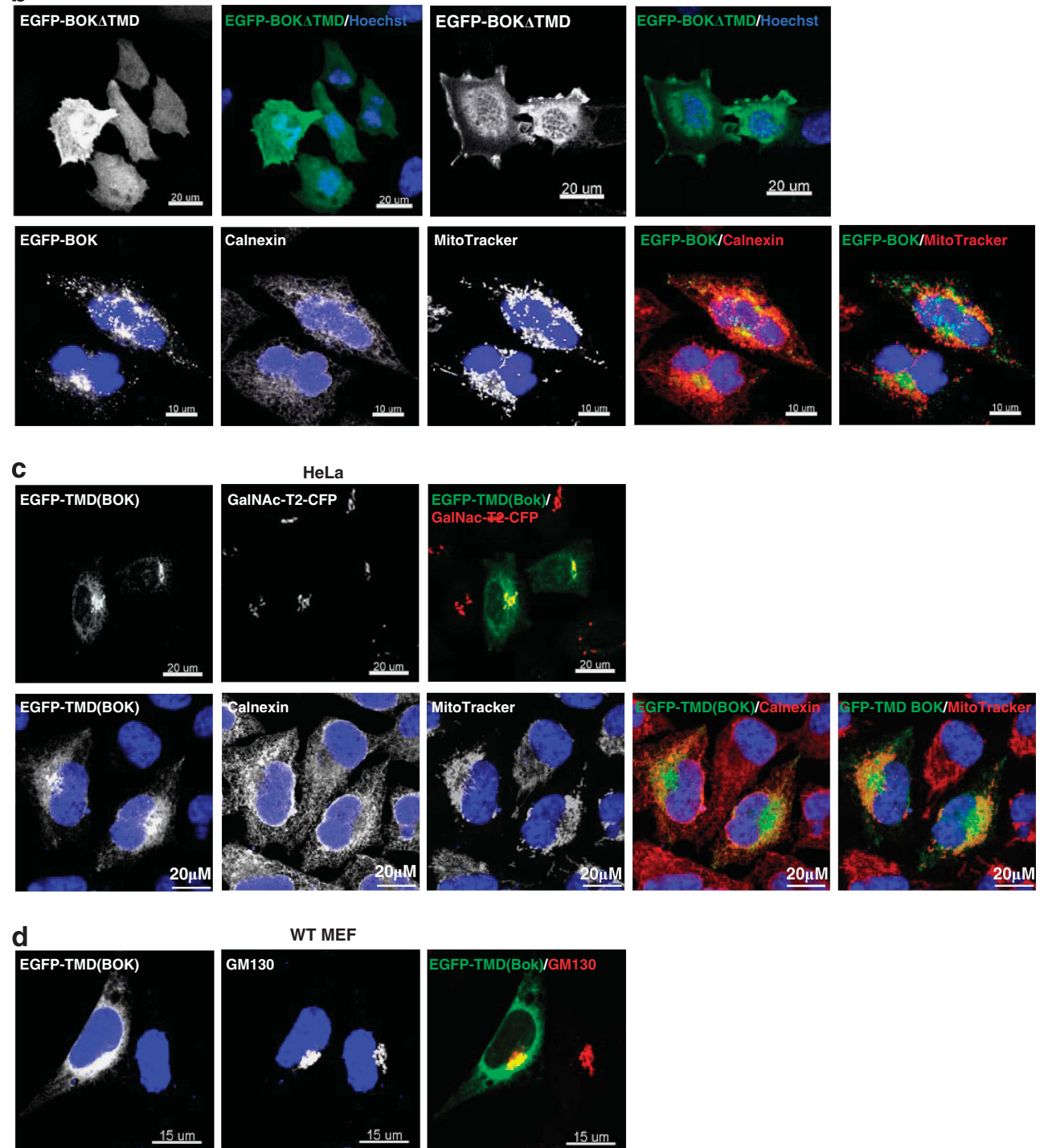

WT MEF
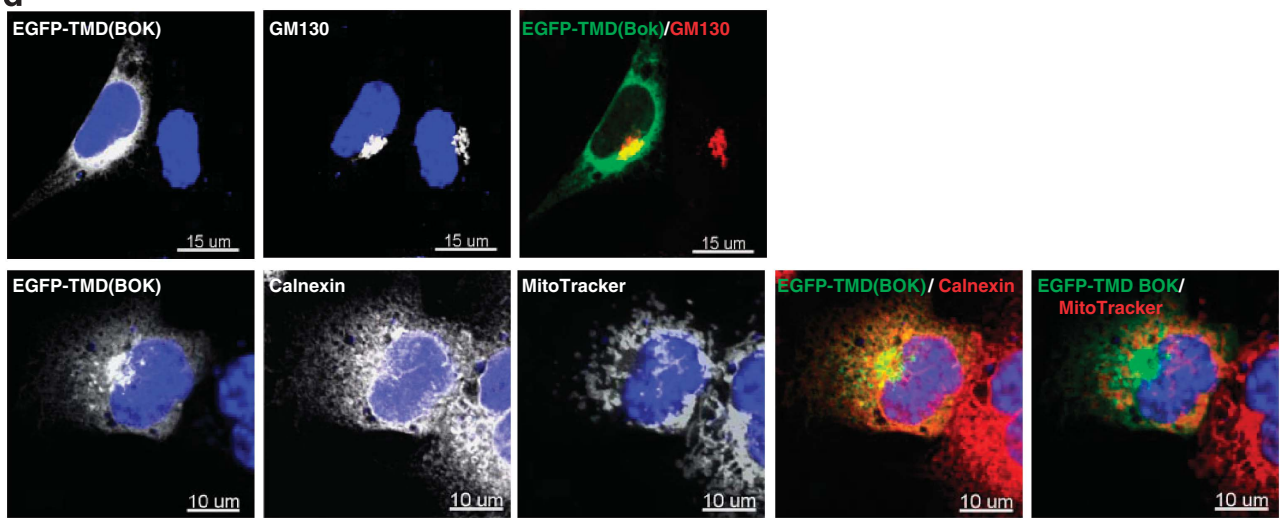

Figure 5 The transmembrane domain of BOK is necessary and sufficient for membrane targeting. (a) Amino-acid sequences of the C-terminal transmembrane domains (TMD) of BOK, BCL-2, BCL-X, BAX and BAK. Positively charged amino acids are printed in bold. (b) Confocal scanning micrographs of HeLa cells and SV40-immortalized $B o k^{-1-}$ MEF transfected with pEGFP-BOK $\triangle T$ TMD for 18 and $8 \mathrm{~h}$, respectively, and stained as indicated. pEGFP-BOK $\Delta$ TMD shows cytosolic and nuclear localization (Hoechst 33342, blue). EGFP-(WT)BOK is shown as control. (c) HeLa and HeLa/GalNAc-T2-CFP cells were transfected with $\mathrm{pEGFP-TMD(BOK)} \mathrm{for} 24 \mathrm{~h}$ and stained with antibodies to calnexin (ER), MitoTracker Deep Red 633 (mitochondria) and Hoechst 33342 (DNA). EGFP-TMD(BOK) localizes extensively to Golgi membranes and ER membranes. (d) Confocal micrographs of SV40-immortalized WT MEF transiently transfected with GFP-TMD(BOK) for $24 \mathrm{~h}$ and stained with the indicated organelle markers 


\section{WT MEF}

a
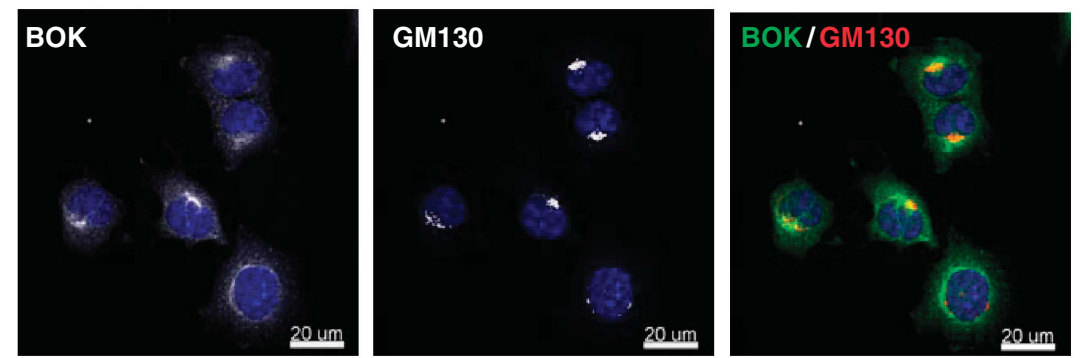

b
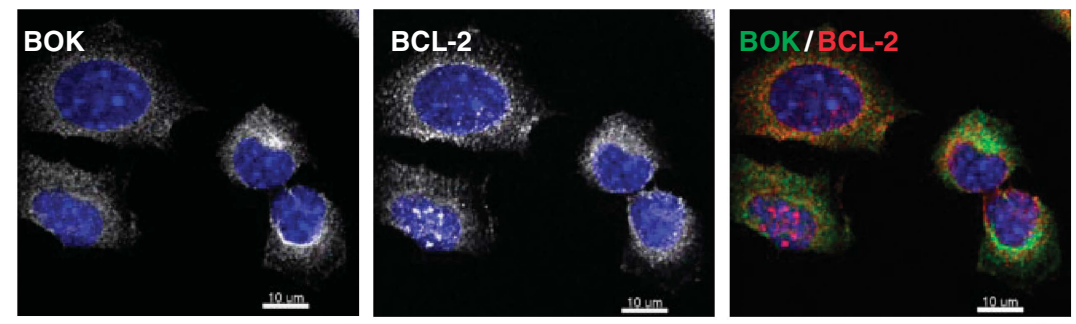

C
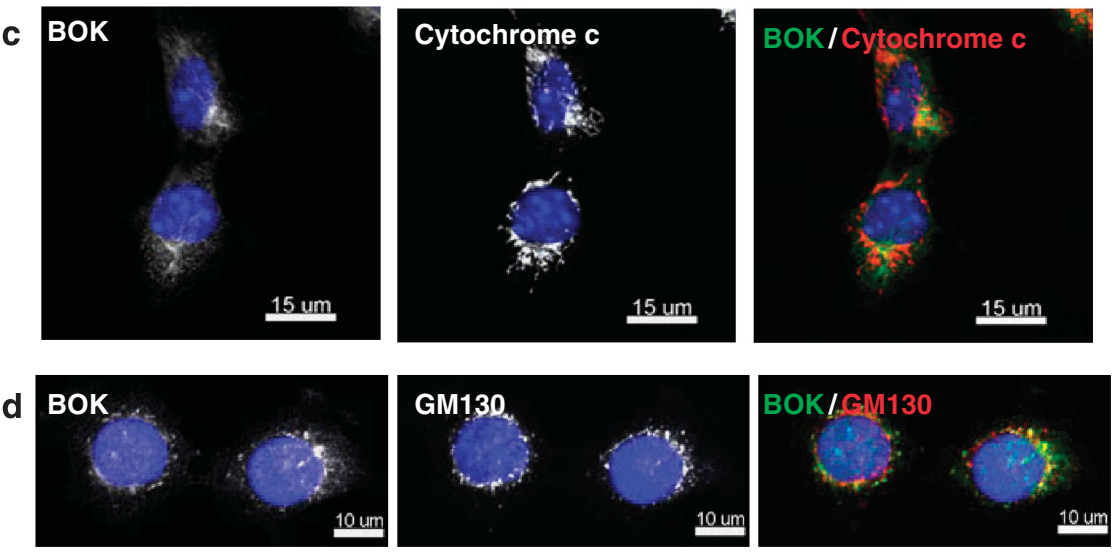

e

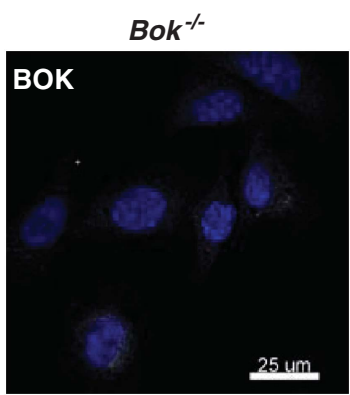

Figure 6 Endogenous BOK strongly associates with the Golgi and ER compartments. (a-c) Confocal scanning micrographs of SV40-immortalized WT MEF stained with Hoechst 33342 (nuclei) and antibodies against BOK, GM130 (cis-Golgi marker), BCL-2 and cytochrome c. (d) WT SV40 MEF were treated with $0.3 \mu \mathrm{g} / \mathrm{ml}$ brefeldin A for $15 \mathrm{~h}$ and stained with anti-BOK and anti-GM130 antibodies and Hoechst 33342. (e) SV40-immortalized Bok ${ }^{-1}$ MEF were stained with antibodies to BOK and Hoechst 33342

genuine BAX-like protein that would be able to substitute for the combined loss of BAX and BAK in triggering apoptosis. Numerous studies have shown that $\mathrm{Bax}^{-/-} \mathrm{Bak}^{-/-}$cells, including MEF or lymphocytes, are highly resistant to diverse apoptotic stimuli, even though they express detectable levels of endogenous BOK (Ke et $\mathrm{al}^{20}$ and Supplementary Figure S1). This strongly indicates that intrinsic apoptosis requires the presence of either BAX or BAK for its execution and hints at the inability of BOK to substitute for BAX/BAK function.
We tested the effect of BOK overexpression in SV40 MEF and FDM cells. Whereas WT FDM were susceptible to BOKinduced killing, $\mathrm{Bax}^{-/-} \mathrm{Bak}^{-/-}$FDM were completely refractory to enforced $\mathrm{BOK}$ expression. $\mathrm{Bax}^{-/-} \mathrm{Bak}^{-/-}$ MEF were also largely protected from BOK-induced killing, although a minor extent of cell death was observed. In contrast to FDM cells, the pan-caspase inhibitor Q-VD-OPh (used at $25 \mu \mathrm{M}$ ) only partially protected WT MEF from BOKinduced killing. The low extent of cell death seen in the 
a

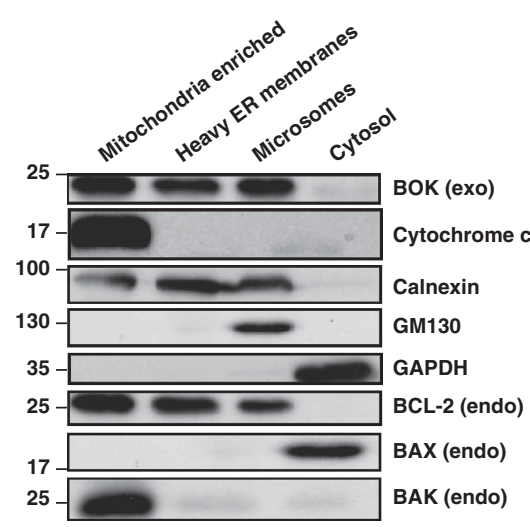

b

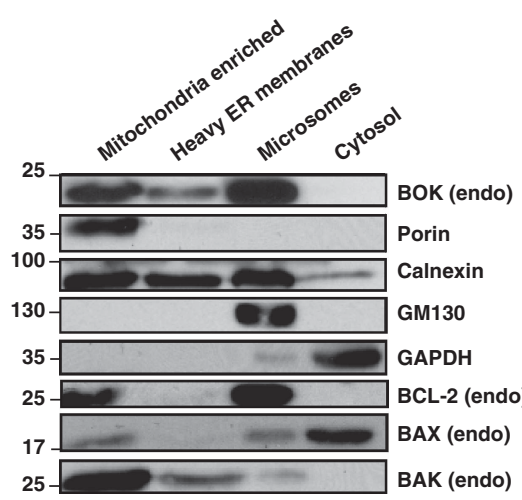

C WT Primary Hepatocytes

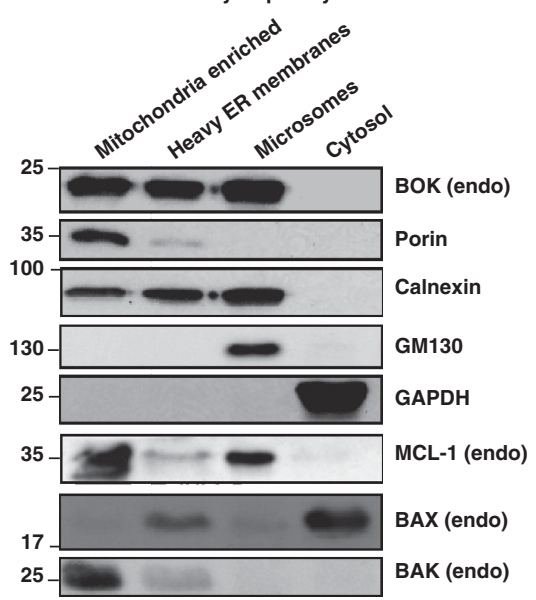

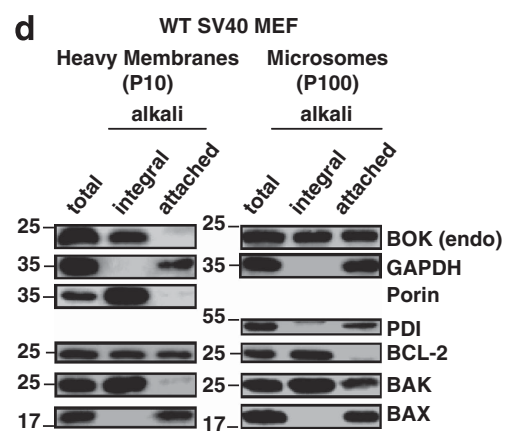

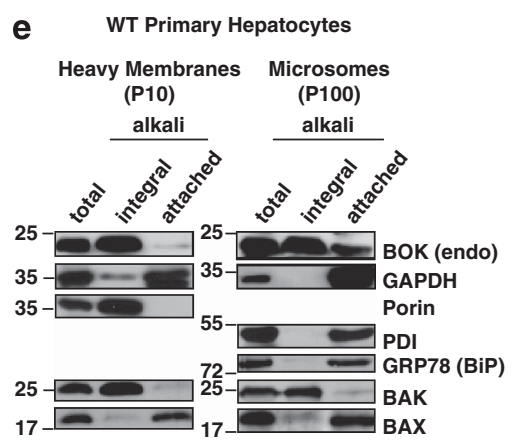

g

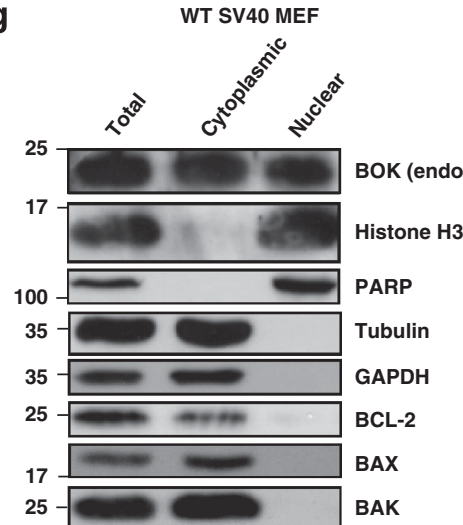

f

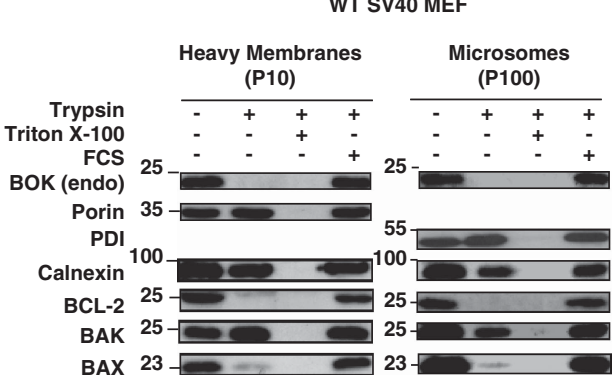

Figure 7 Analysis of the localization of overexpressed and endogenous BOK by subcellular fractionation and membrane insertion assays. Anti-BOK Western blots of subcellular fractions prepared from SV40-immortalized WT MEF/5xUAS-FLAG-BOK cells after FLAG-BOK induction with 0.1 $\mu$ M 4-OHT for $14 \mathrm{~h}$ (a), SV40 WT MEF (b) and primary hepatocytes freshly isolated from young adult C57BL/6 (WT) mice (c). Membranes were reprobed with antibodies to mouse BCL-2, MCL-1, BAX and BAK for comparison. Reprobing of the membranes with antibodies to Porin or cytochrome c (mitochondria), calnexin (ER), GM130 (Golgi) and GAPDH (cytosol) served as controls for the purity of the subcellular fractions. Heavy $P_{10}$ and light $P_{100}$ membrane fractions from SV40 WT MEF (d) and mouse primary hepatocytes (e) were extracted directly with detergent (total) or first treated with sodium carbonate solution ( $\mathrm{pH} 12$ ) to remove loosely attached membrane proteins. Remaining membrane proteins were lysed in detergent and all fractions analyzed by Western blotting for endogenous BOK and indicated proteins that served as controls for integrally inserted membrane proteins (Porin, BAK, $\mathrm{BCL}-2)$, or loosely attached and soluble proteins (BAX, GAPDH). BiP and PDI are luminal ER proteins and probing for them served as a control for vesicle integrity. (f) Heavy and light membranes were prepared from SV40 WT MEF and membrane proteins facing the cytosol, including endogenous BOK, were digested with $0.01 \%$ trypsin. (g) Purified nuclear and cytoplasmic fractions were prepared from SV40 WT MEF. A large portion of endogenous BOK was found in the purified nuclear fraction. The purity of the fractions was controlled by reprobing the membrane with antibodies against Histone H3 and PARP (nuclear) as well as Tubulin and GAPDH (cytoplasmic). In contrast to BOK, no endogenous BCL-2, BAX or BAK could be detected in the nuclear fraction

absence of BAX/BAK could therefore be due to additional, caspase-independent death pathways that, in fact, have been suggested in early reports on BOK. ${ }^{16,17,40}$ Importantly,
$\mathrm{Bax}^{-/-} \mathrm{Bak}^{-/-}$MEF and FDM overexpressing BOK were still highly resistant to classical apoptotic stimuli. This indicates that BOK function cannot substitute for the 
a

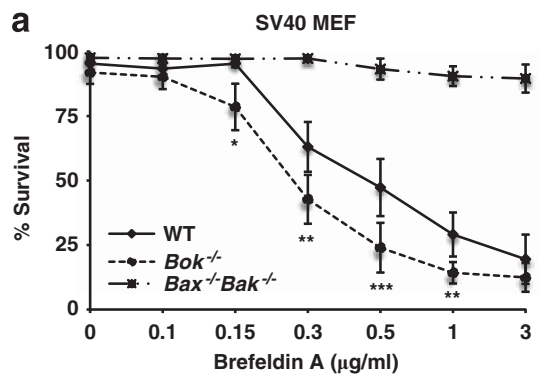

b

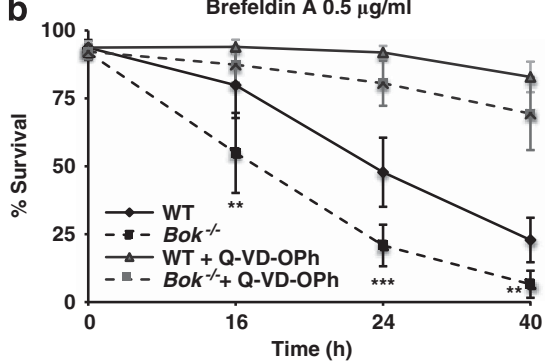

C
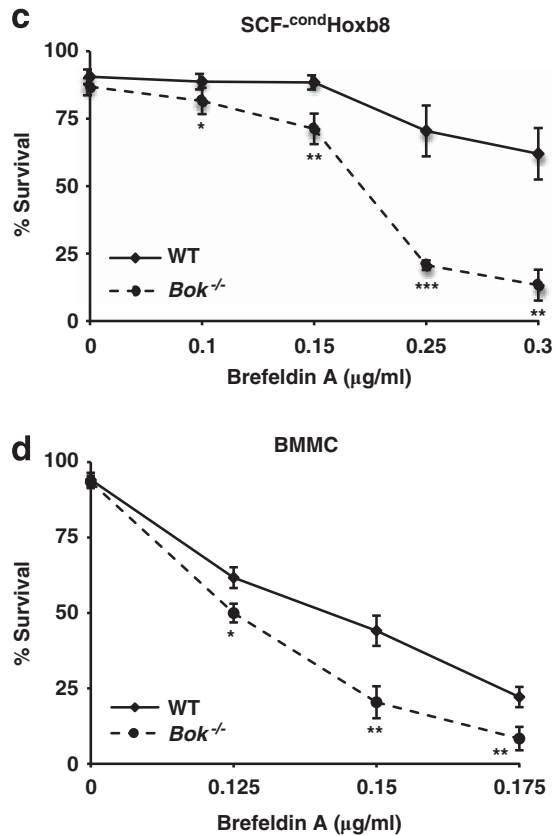

\section{e}
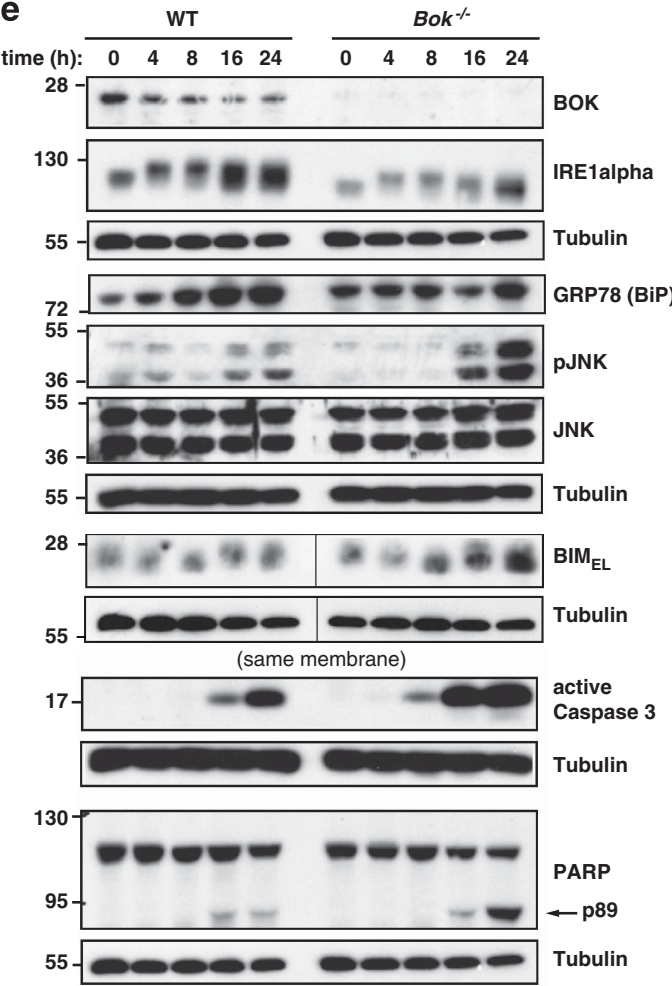

Figure 8 BOK-deficient cells show an atypical response to treatment with brefeldin A. (a) The survival of SV40-immortalized WT, Bok ${ }^{-1-}$ and Bax ${ }^{-1-} B a k^{-1-}$ MEF treated with the indicated doses of brefeldin A for $24 \mathrm{~h}$ was quantified by flow cytometry (GFP-Annexin V/PI negative cells). (b) Time kinetics of cell survival of SV40 WT and Bok $^{-1-}$ MEF treated with $0.5 \mu \mathrm{g} / \mathrm{ml}$ brefeldin A with or without $25 \mu \mathrm{M}$ Q-VD-OPh. (c) WT and Bok ${ }^{-1-}$ SCF- ${ }^{\text {cond }}$ Hoxb8-immortalized myeloid progenitors were treated with the indicated doses of brefeldin A for $18 \mathrm{~h}$. Cell survival was determined by GFP-Annexin V/PI staining followed by flow cytometric analysis. (d) Brefeldin A dose-response curves (treatment for $24 \mathrm{~h}$ ) of ex vivo generated bone marrow-derived mast cells (BMMC) derived from WT or Bok ${ }^{-1-}$ mice. (e) Western blot analysis of protein lysates prepared from SV40 WT and Bok ${ }^{-1-}$ MEF that had been treated with $3 \mu \mathrm{g} / \mathrm{ml}$ brefeldin A for the indicated times. Data are representative of three independent experiments using different SV40-immortalized MEF lines. All quantitative data (dose responses and time kinetics) are presented as means \pm S.D. of at least five (MEF) or three (BMMC,

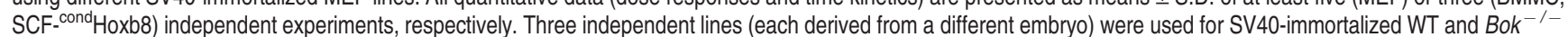
MEF, respectively. Significance was determined by unpaired Student's $t$-test $\left({ }^{* \star \star} P<0.005,{ }^{* \star} P<0.01\right.$ and $\left.{ }^{\star} P<0.05\right)$

combined loss of BAX and BAK and indicate that BOK may act upstream of BAX/BAK. This is in line with our observation that BOK overexpression increases the levels of the BH3-only proteins BIM and PUMA (Supplementary Figure S7). Alternatively, BOK may be activated by selective cell death stimuli that remain to be identified.
BOK has been reported to interact with MCL-1 and BFL-1/ A1 but not with BCL-2 or BCL- $\mathrm{X}_{\mathrm{L}} \cdot{ }^{16,17} \mathrm{~A}$ BH3-domain deletion mutant of BOK was unable to interact with MCL-1 and BFL1/ A1 but, surprisingly, still retained its killing activity. ${ }^{23}$ Although we did not detect interactions between BOK and other BCL-2 family members, we found that HA-BOK and FLAG-BOK 
co-immunoprecipitated in a $\mathrm{BH} 3$ domain-dependent manner, as the interaction was disrupted by the BOK(D76A) point mutation. This supports the idea that, similarly to BAX and BAK, BOK may form homodimers/-oligomers. Interestingly, however, $B O K(D 76 A)$ retained its ability to kill cells, indicating that BOK may induce cell death as a monomer. This is in contrast to BAX and BAK, where loss of killing function seems to invariably correspond with failure to oligomerize. ${ }^{30,41,42}$

We present evidence that the TMD of BOK is a targeting device both necessary and sufficient to target the protein to its intracellular destinations. Interestingly, the TMD of BOK has high affinity for Golgi and ER membranes. Accordingly, substantial portions of full-length BOK are localized on the ER and Golgi and associated membranes of the secretory system. Even though several BCL-2 family members, most notably BCL-2 but also BAX and BAK, were reported to bind to the $E R /$ nuclear outer membranes where they exert specific functions, ${ }^{11,34,37,43,44}$ the Golgi targeting of BOK is of potential interest. Furthermore, whereas relatively minor fractions of $B A X$ and $B A K$ are detectable on the $E R$, a large portion of total BOK resides on the Golgi/ER. This indicates that BOK may exert specific functions on these organelles. Both BAX and BAK were shown to interact with $\operatorname{IRE} 1 \alpha$ at the $E R$ and $\mathrm{Bax}^{-/-} \mathrm{Bak}^{-/-}$cells showed defective IRE $1 \alpha$-signaling and increased cellular damage upon ER stress. ${ }^{45}$ We observed a similar defective ER stress response in $\mathrm{Bok}^{-/-}$cells, which was most pronounced after treatment with brefeldin A, a drug that has a strong impact on the Golgi/ER compartments. It will be interesting to uncover the functions that BOK exerts at these locations, both in healthy and in dying cells.

It is important to mention that our data do not exclude mitochondrial localization and function of BOK. In analogy to several BCL-2 family members localizing to multiple organelles, it is conceivable that BOK also localizes to mitochondria. Indeed, particularly when BOK was overexpressed, we found some colocalization with mitochondrial markers. Moreover, in subcellular fractionation experiments, BOK was also prominent in mitochondria-enriched fractions. However, these fractions were still significantly positive for the ER marker calnexin. As the ER membranes interact with mitochondria through so-called mitochondria-associated membranes (MAM), ${ }^{46}$ it is difficult to prepare MAM-free mitochondrial fractions and, hence, further investigation is needed to quantify the exact amount of mitochondrial BOK.

Irrespective of its subcellular localization, our data from $\mathrm{Bax}^{-/-} \mathrm{Bak}^{-/-}$cells indicate that BOK cannot compensate for the combined loss of BAX and BAK in triggering MOMP and apoptosis. Instead, we show that BOK-induced apoptosis largely relies on the presence of BAX or BAK. BOK may therefore function upstream of $B A X / B A K$ and may control the transmission of ER/Golgi-derived apoptotic signals to mitochondria. This hypothesis is supported by our observation that overexpressed BOK leads to the fragmentation of ER and Golgi upstream of caspase activation. However, when BOK is missing, the Golgi may be dismantled in conditions of stress in an inappropriate manner, thereby causing increased ER stress and activation of $\mathrm{BH} 3-$ only proteins, leading to apoptosis. ${ }^{47}$

Little is known about the stress stimuli and mechanisms that lead to transcriptional or post-translational activation of BOK.
In order to test whether BOK acts within the same pathway(s) as BAX and BAK or independently, triple-knockout mice lacking Bok, Bax and Bak will have to be generated and their phenotype compared with those of $\mathrm{Bax}^{-/-} \mathrm{Bak}^{-/-}$animals. Besides its cytoplasmic localization, we also found BOK in purified nuclear fractions. Given the existence of BOK-deficient mice, the possible functions of BOK within the nucleus, including putative non-apoptotic roles (e.g. as reported for trophoblast cell proliferation ${ }^{48}$ ) can now be analyzed.

Finally, given that BOK has recently been identified as a candidate tumor suppressor ${ }^{27}$ and increasing evidence emerges for non-apoptotic roles of BCL-2 family proteins, especially at non-mitochondrial sites, it will be interesting to test whether the putative tumor-suppressor function of BOK is restricted to its pro-apoptotic function or whether it involves new functions yet to be discovered.

\section{Materials and Methods}

Mice and reagents. Mice used for the isolation of bone marrow, primary hepatocytes and embryonic fibroblasts were maintained under specific pathogenfree conditions in individually ventilated cages. The generation of $\mathrm{Bok}^{-1-}$ mice on an inbred C57BL/6 genetic background using C57BL/6-derived ES cells was described. ${ }^{20}$ Animal experiments were reviewed and approved by the animal experimentation review board of the canton of Bern (41/08 and BE31/11).

High glucose Dulbecco's Modified Eagle Medium (DMEM, containing GlutaMAX), RPMI 1640 medium (containing GlutaMAX), William's E medium (containing GlutaMAX), HEPES-buffered saline solution (HBSS), trypsin solution $0.05 \%$ and penicillin/streptomycin $100 \times$ stock solution were purchased from Gibco (Life Technologies Europe, Zug, CH). Fetal calf serum (FCS, PAA Clone, endotoxin levels $<1 \mathrm{EU} / \mathrm{ml}$ ) and puromycin were purchased from PAA (PAA Laboratories $\mathrm{GmbH}$, Pasching, AT). 4-hydroxytamoxifen (4-OHT, no. H7904), 2-mercaptoethanol, brefeldin $\mathrm{A}$, dexamethasone and propidium iodide were purchased from Sigma-Aldrich Chemie $\mathrm{GmbH}$ (Buchs, CH). Q-VD-OPh was from SM Biochemicals (Anaheim, CA, USA). Staurosporine was purchased from Enzo LifeSciences AG (Lausen, $\mathrm{CH}$ ). Recombinant $\mathrm{His}_{6}$-tagged GFP-Annexin $\mathrm{V}$ was purified as described by Egger et al. ${ }^{49}$

Expression constructs and site-directed mutagenesis. Mouse Bok cDNA in the pCMV6 eukaryotic expression vector was purchased from Origene (Rockville, MD, USA) with correct nucleotide sequence confirmed by DNA sequencing (Microsynth AG, Balgach, CH). Using a PCR-based strategy employing the Pwo SuperYield polymerase (Roche Diagnostics AG, Rotkreuz, $\mathrm{CH}$ ), a FLAG-tag (DYKDDDDK) was added to the N-terminus of Bok and the resulting FLAG-Bok amplicon subcloned into the pcDNA3.1 expression vector using BamHI and EcoRI. Primer sequences: forward primer $5^{\prime}$-CTGGGATCC ATGGACTACAAGGACGATGACGATAAGGAGGTGCTGCGGCGCTCTTC, reverse primer 5'-CTGGAATTCTCATCTCTCTGGCAACAACAGGAAG. Using the same strategy, the Bok C-terminal deletion mutant, FLAG-Bok $\triangle T M D$, was generated using the reverse primer 5'-CTGGAATTCTCAGTGGGAGCGGAAGCCAGGATC. The pEGFP-TMD(BOK) construct was generated by PCR amplifying the transmembrane domain (consisting of its $35 \mathrm{C}$-terminal amino acids) encoding sequence of the Bok gene using the template $\mathrm{pCMV} 6 / \mathrm{Bok}(\mathrm{mm})$ with the forward primer $5^{\prime}$-GATCT CGAGGTGGTCAGCACAGATC and the reverse primer 5'-GCAGAATTC TCATCTCTCTGGCAAC and subcloned into the PEGFP(C3) mammalian expression vector using Xhol and EcoRI. FLAG-Bok and FLAG-Bok $\triangle T M D$ cDNA were subcloned from FLAG-Bok/pcDNA3.1 and FLAG-Bok $\triangle T M D / p c D N A 3.1$ into the pF-5xUAS-SV40-puro-GEV16 lentiviral vector using BamHI and Xbal/Nhel or into the pEGFP(C3) expression vector using HinDIII and EcoRI. The Bok(D76A) single amino-acid substitution was introduced into FLAG-Bok/pcDNA3.1 using QuikChange Lightening Site-Directed Mutagenesis Kit (Agilent Technologies, Basel, $\mathrm{CH}$ ) following the manufacturer's instructions; forward primer: $5^{\prime}$-CTGCGCTTGGGAGCTGAGCTGGAGCAG, reverse primer: 5'-CTGCTCCAGCTCAGCTCCCAAGCGCAG. The coding sequences of all subcloned or mutated plasmids was verified by DNA sequencing (Microsynth $A G$ ).

Cell culture. Bax ${ }^{-1-} \mathrm{Bak}^{-/-}$and matching wild-type SV40 LT-immortalized mouse embryo fibroblasts (MEF) were kindly provided by Dr Christoph Borner 
(Freiburg, Germany). Primary C57BL/6 wild type and Bok $\mathrm{k}^{-1-} \mathrm{MEF}$ were isolated from 14.5-day-old embryos and immortalized with SV40 LT/pSG5. At least three independent lines, each derived from a different embryo were generated for each genotype. WT and $\mathrm{Bax}^{-1-} \mathrm{Bak}^{-/-}$FDM cells were kindly provided by Dr Paul Ekert (Melbourne, Australia). All cells were cultured at $37^{\circ} \mathrm{C}$ in a humidified $5 \%$ $\mathrm{CO}_{2}$ atmosphere. HeLa cells were cultured in DMEM/GlutaMAX high glucose medium supplemented with 10\% FCS and penicillin/streptomycin. SV40immortalized MEF were cultured in DMEM/GlutaMAX high glucose medium supplemented with $5 \%$ FCS and penicillin/streptomycin.

Isolation and cultivation of primary hepatocytes. Primary mouse hepatocytes were isolated from 6-12-week-old mice by a collagenase perfusionbased method as described in..$^{50}$ The purity of isolated hepatocytes was routinely $>95 \%$, as judged by cellular morphology of the attached cells. Isolated hepatocytes were plated on gelatin-coated flasks in William's $\mathrm{E}$ medium supplemented with $10 \% \mathrm{FCS}, 100 \mathrm{nM}$ dexamethasone, $2 \mathrm{mM}$ L-glutamine and $1 \%$ penicillin/streptomycin solution. After the cells adhered (after $4 \mathrm{~h}$ ), they were washed and experiments immediately started in complete William's $\mathrm{E}$ medium (without dexamethasone) at $37^{\circ} \mathrm{C}$ under $5 \% \mathrm{CO}_{2}$.

Generation of SCF- ${ }^{\text {cond }}{ }^{H o x b 8}$ cell lines and bone marrowderived mast cells. See Online Supplementary Section.

Transient transfection, immunofluorescence staining and confocal microscopy. HeLa cells were grown on 12-mm glass coverslips and transiently transfected with $0.4 \mu \mathrm{g}$ of plasmid DNA and $1.6 \mu$ l Fugene HD transfection reagent (Roche Diagnostics, Rotkreuz, CH) in 24-well plates. SV40immortalized MEF were transfected with $0.4 \mu \mathrm{g}$ of plasmid DNA and $1.6 \mu$ Metafectene Pro (Biontex Laboratories $\mathrm{GmbH}$, Martinsried, DE). At various times after transfection, cells were stained with $370 \mathrm{nM}$ MitoTracker Deep Red 633 or $500 \mu \mathrm{M}$ LysoTracker Red DND-99 (Life Technologies), fixed for 10 min with $4 \%$ paraformaldehyde, permeabilized with $0.05 \%$ saponin for 5 min and treated with ice-cold acetone for $10 \mathrm{~min}$. The cells were then incubated over night at $4{ }^{\circ} \mathrm{C}$ with the following primary antibodies diluted in PBS containing $1 \%$ bovine serum albumin: mouse anti-FLAG (clone M2, no. F1804) and rabbit anti-calnexin (no.C4731) from Sigma-Aldrich, rabbit anti-DYKDDDDK tag, rabbit anti-BOK (described in; ${ }^{20}$ adsorbed on PVDF membrane containing Bok ${ }^{-/-}$MEF lysate for IF applications), mouse anti-mouse BCL-2 (clone 10C4, BioLegend, San Diego, CA, USA), mouse anti-cytochrome $\mathrm{C}$ (clone 6H2.B4) and mouse anti-GM130 (clone 35/GM130) from BD Biosciences (Allschwil, CH). Secondary antibodies, Alexa Fluor 488- or 555-conjugated goat anti-mouse or goat anti-rabbit IgG (Life Technologies) antibodies were added for $1 \mathrm{~h}$ at RT. Nuclear DNA was stained using $2 \mu \mathrm{g} / \mathrm{ml} \mathrm{Hoechst} 33342$ (Sigma-Aldrich). Coverslips were mounted using Glycergel (Dako, Baar, CH) or Prolong Gold antifade reagent (Life Technologies). Images were acquired using a Zeiss LSM 510 laser confocal microscope with a $63 \times$ oil immersion objective (Carl Zeiss AG, Feldbach, $\mathrm{CH}$ ) and analyzed using the IMARIS software (Bitplane, Zürich, $\mathrm{CH}$ ).

Quantification of cell death by flow cytometry. Cells were washed with Annexin V staining buffer $\left(150 \mathrm{mM} \mathrm{NaCl}, 4 \mathrm{mM} \mathrm{KCl}, 2.5 \mathrm{mM} \mathrm{CaCl}_{2}, 1 \mathrm{mM}\right.$ $\mathrm{MgSO}_{4}, 15 \mathrm{mM}$ HEPES pH 7.2, $2 \%$ FCS and $10 \mathrm{mM} \mathrm{NaN}_{3}$ ) and incubated with GFP-Annexin V diluted in staining buffer for at least $20 \mathrm{~min}$ on ice in the dark. Cells were then washed in Annexin V staining buffer and resuspended in $200 \mu \mathrm{l}$ staining buffer. Propidium iodide was added to a final concentration of $2 \mu \mathrm{g} / \mathrm{ml}$ and cells examined by flow cytometry using a FACSCalibur (BD Biosciences). GFP. Annexin V-and propidium iodide-negative cells were considered as viable cells.

Immunoprecipitation. $7 \times 10^{5} \mathrm{HEK} 293 \mathrm{~T}$ cells were seeded in 6-well plates and transfected on the following day with a total of $2 \mu \mathrm{g}$ DNA plus transfection reagent (Fugene HD, Roche Diagnostics) at a ratio of $1: 4$. Cells were lysed in $300 \mu \mathrm{l}$ IP lysis buffer $(50 \mathrm{mM}$ Tris $/ \mathrm{HCl} \mathrm{pH} 7.4,150 \mathrm{mM} \mathrm{NaCl}, 1 \mathrm{mM}$ EDTA, $1 \%$ Triton X-100, complete protease inhibitor cocktail (Roche Diagnostics) and $1 \mu \mathrm{g} / \mathrm{ml}$ pepstatin) for $15 \mathrm{~min}$ on ice and lysates cleared by centrifugation. Lysates were precleared using $50 \mu \mathrm{l}$ of a $50 \%$ slurry of Protein G sepharose beads (GE Healthcare, Glattbrugg, $\mathrm{CH}$ )) for $1 \mathrm{~h}$ at $4{ }^{\circ} \mathrm{C}$ on a rotating wheel and then incubated with either mouse anti-FLAG (clone M2, Sigma-Aldrich) or rat anti-HA (clone $3 \mathrm{~F} 10$, Roche Diagnostics) antibodies for $2 \mathrm{~h}$ on ice. $50 \mu \mathrm{l}$ of protein $\mathrm{G}$ sepharose beads ( $50 \%$ slurry) were added and the mixture incubated at $4{ }^{\circ} \mathrm{C}$ for a minimum of $2 \mathrm{~h}$ on a rotating wheel. Beads were washed three times in IP lysis buffer and boiled for $5 \mathrm{~min}$ in $50 \mu \mathrm{l}$ of $2 \times$ Lämmli buffer containing $100 \mathrm{mM}$ DTT.

Subcellular fractionation. Subcellular fractionation was performed as described in. ${ }^{11}$ Briefly, a total of $1 \times 10^{7}$ SV40-immortalized MEF or $5 \times 10^{6}$ primary hepatocytes were harvested, washed twice in phosphate-buffered saline (PBS) and resuspended in MSH-MD buffer $(210 \mathrm{mM}$ mannitol, $70 \mathrm{mM}$ sucrose, $20 \mathrm{mM}$ HEPES, $1 \mathrm{mM}$ EDTA, pH 7.4, $\mathrm{MgCl}_{2}, 2 \mathrm{mM}$ DTT) supplemented with protease inhibitor cocktail (Complete, Roche), $1 \mu \mathrm{g} / \mathrm{ml}$ pepstatin, $2 \mathrm{mM}$ sodium orthovanadate and $50 \mathrm{mM}$ sodium fluoride). Cells were mechanically lysed by passing them through a $23 \mathrm{G}$ (MEF) or $25 \mathrm{G}$ (hepatocytes) needle. Nuclei and cellular debris were removed by centrifugation at $500 \times \mathrm{g}$ for $5 \mathrm{~min}$. The postnuclear supernatant (PNS) was centrifuged at $10000 \times \mathrm{g}$ for $15 \mathrm{~min}$, and the resulting crude mitochondrial pellet washed twice in PBS. To further purify mitochondria, crude mitochondria were laid on top of a 1-2 $\mathrm{M}$ linear sucrose gradient and ultracentrifuged at $50000 \times \mathrm{g}$ for $90 \mathrm{~min}$. Enriched mitochondria, which banded at a region corresponding to $1.4 \mathrm{M}$ sucrose, and a visible band at about $1.0 \mathrm{M}$ sucrose, containing ER-derived heavy membranes, were carefully collected and diluted to $0.25 \mathrm{M}$ sucrose prior to centrifugation at $50000 \times \mathrm{g}$ for $30 \mathrm{~min}$. The resulting pellets were solubilized in hot $\mathrm{H} 8$ buffer $(20 \mathrm{mM}$ Tris/ $\mathrm{HCl} \mathrm{pH}$ 7.5, $2 \mathrm{mM}$ EGTA, $2 \mathrm{mM}$ EDTA and 1\% SDS, $1 \mathrm{mM}$ DTT, protease inhibitor cocktail (Complete, Roche), $1 \mu \mathrm{g} / \mathrm{ml}$ pepstatin, $2 \mathrm{mM}$ sodium orthovanadate and $50 \mathrm{mM}$ sodium fluoride). Centrifugation of the post-mitochondrial supernatant (PMS) at $100000 \times \mathrm{g}$ for $30 \mathrm{~min}$ yielded the microsomal pellet $\left(\mathrm{P}_{100}\right)$ and the cytosolic fraction $\left(\mathrm{S}_{100}\right)$. The microsome pellet was washed three times in MSH-MD buffer and lysed in hot $\mathrm{H} 8$ buffer. Nuclear fractionation was performed as described by Rosner et al. ${ }^{51}$ Protein concentration was measured using the Bradford assay. A total of $25 \mu \mathrm{g}$ protein per fraction was separated on denaturing SDS-PAGE gels and analyzed by Western blotting.

\section{Sodium carbonate extraction (alkaline treatment) and trypsin} treatment. Crude mitochondrial $\left(P_{10}\right)$ and microsomal $\left(P_{100}\right)$ fractions from SV40-immortalized MEF or primary hepatocytes were prepared as described above, resuspended in $0.1 \mathrm{M}$ sodium carbonate solution $(\mathrm{pH} 12)$ and incubated for $20 \mathrm{~min}$ on ice. After centrifugation at $20000 \times \mathrm{g}$ for $15 \mathrm{~min}$ at $4{ }^{\circ} \mathrm{C}$, the supernatant (containing the alkali-extractable proteins) was titrated back to a neutral $\mathrm{pH}$ with $1 \mathrm{M} \mathrm{HCl}$. The pellet (containing the alkali-resistant fraction) was washed three times in MSH-MD buffer and then solubilized in hot $\mathrm{H} 8$ buffer. $10 \%$ of each fraction was used for a total lysate control. For trypsin treatments, crude mitochondrial and microsomal fractions were resuspended in complete MSH-MD buffer and left on ice for $30 \mathrm{~min}$ with or without $0.1 \mathrm{mg} / \mathrm{ml}$ trypsin. Protein concentration was measured using the Bradford assay. A total of $25 \mu \mathrm{g}$ protein per fraction was separated on denaturing SDS-PAGE gels and analyzed by Western blotting.

Gel electrophoresis and immunoblotting. Total protein extracts were

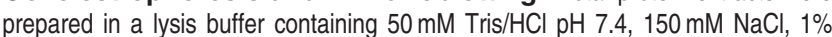
NP-40, $0.1 \%$ SDS, complemented with protease inhibitors (Roche Complete protease inhibitor cocktail plus $1 \mu \mathrm{g} / \mathrm{ml}$ pepstatin) and phosphatase inhibitors (2 mM sodium orthovanadate and $50 \mathrm{mM}$ sodium fluoride). Protein concentration was determined using a BCA assay (Fisher Scientific, Wohlen, $\mathrm{CH}$ ) and proteins were denatured by adding $4 \times$ reducing ( $100 \mathrm{mM}$ DTT) Lämmli buffer and boiling the samples for $5 \mathrm{~min}$. A total of $30 \mu \mathrm{g}$ protein per extract was separated on denaturing SDS-PAGE gels. Proteins were transferred to PVDF transfer membranes $(0.45 \mu \mathrm{m}$, Merck Millipore, Zug, CH). For Western blotting, membranes were probed with the following primary antibodies: mouse antiBCL-2 (clone 10C4, BioLegend); rabbit anti-GRP78/BiP and rat anti-BIM (clone 3C5) from Enzo LifeSciences; rabbit anti-PUMA (Pro-Sci, no. 3043); rabbit anticalnexin (no. C4731), mouse anti-tubulin (clone B-5-1-2) and mouse anti-FLAG (M5) from Sigma-Aldrich; rabbit anti-caspase-3 (no. 9662), rabbit anti-active caspase-3 (no. 9661), rabbit anti-active caspase-7 (no. 9491), rabbit anti-IRE1 $\alpha$ (clone 14C10), rabbit anti-JNK/SAPK(no. 9252) and mouse anti-phospho-JNK/ SAPK (clone G9, no. 9255) from Cell Signaling Technology (Danvers, MA, US); rabbit anti-BAX (\#sc-493) from Santa Cruz Biotechnologies (Dallas, TX, US); mouse anti-cytochrome $\mathrm{c}$ (clone $7 \mathrm{~h} 8.2 \mathrm{C} 12$ ) and mouse anti-PARP (clone $\mathrm{C} 2-10$ ) from BD Biosciences; mouse anti-porin (clone 89-173/016) from Merck Millipore; mouse anti-GAPDH (clone 6C5) and rabbit anti-BAK (Bak NT) from Merck Millipore; rat anti-mouse MCL-1 (clone 14C11, kind gift from Dr. D Huang, Melbourne, Australia); rabbit polyclonal antibody raised against amino acids 19-32 
of mouse BOK (described in $\mathrm{Ke}$ et $\mathrm{al}^{20}$ ) and a rabbit monoclonal anti-BOK (RabMab BOK-1-5, raised against aa 19-32 of mouse BOK). Secondary antibodies specific to mouse, rat or rabbit $\mathrm{lgG}$ that had been coupled to horseradish peroxidase were obtained from Jackson ImmunoResearch Europe Ltd (Newmarket, UK) and signals were detected by enhanced chemiluminescence (ECL Western blotting substrate, Thermo Scientific and Luminata Forte, Merck Millipore) and detected on photosensitive film (ECL Hyperfilm, GE Healthcare).

\section{Conflict of Interest}

The authors declare no conflict of interest.

Acknowledgements. This study was performed with the support of the Microscopy Imaging Center (MIC), University of Bern. We thank Grant Dewson (Melbourne, Australia) for discussions and critical comments on the manuscript; Shida Yousefi (Bern, $\mathrm{CH}$ ) for help with microscopy; John Silke (Melbourne, Australia) for the lentiviral-inducible expression system; Mario Tschan (Bern, $\mathrm{CH}$ ) for the CAD-G-Whiz lentiviral vector; Nadia Corazza and Anastasia Badmann (Bern, $\mathrm{CH}$ ) for help with isolation of primary hepatocytes; Philippe Bouillet and David Huang (both Melbourne, Australia) for Mcl-1-deficient MEF; David Huang, Lorraine O'Reilly, Paul Ekert (all Melbourne, Australia), Christoph Borner (Freiburg, DE), Frank Essmann (Tübingen, $\mathrm{DE})$, Julia Fernandez-Rodriguez (Gothenburg, SE), Philipp Berger (Villigen, $\mathrm{CH}$ ), Georg Häcker (Freiburg, DE) for plasmids, cell lines, antibodies and reagents. This work was supported by grants and fellowships from the Swiss National Science Foundation (to TK, PP0033_119203), the Australian NHMRC (to AS, 1020363 and 1016701) and the Leukaemia Foundation of Australia (LFA to FK).

\section{Authors Contributions}

TK designed the study and wrote the manuscript. NE designed and performed research and wrote the manuscript. DB performed research. FK, AS and HUS provided crucial reagents, intellectual input and helped to revise the manuscript.

1. Youle RJ, Strasser A. The BCL-2 protein family: opposing activities that mediate cell death. Nat Rev Mol Cell Biol 2008; 9: 47-59.

2. Schinzel A, Kaufmann T, Borner $\mathrm{C}$. Bcl-2 family members: integrators of survival and death signals in physiology and pathology [corrected]. Biochim Biophys Acta 2004; 1644: 95-105.

3. Adams JM, Cory S. Life-or-death decisions by the Bcl-2 protein family. Trends Biochem Sci 2001; 26: 61-66

4. Giam M, Huang DC, Bouillet $\mathrm{P}$. BH3-only proteins and their roles in programmed cell death. Oncogene 2008; 27(Suppl 1): S128-S136.

5. Chipuk JE, Moldoveanu T, Llambi F, Parsons MJ, Green DR. The BCL-2 family reunion. Mol Cell 2010; 37: 299-310.

6. Shamas-Din A, Brahmbhatt $H$, Leber B, Andrews DW. BH3-only proteins: orchestrators of apoptosis. Biochim Biophys Acta 2011; 1813: 508-520.

7. Pop C, Salvesen GS. Human caspases: activation, specificity, and regulation. J Biol Chem 2009; 284: 21777-21781.

8. Riedl SJ, Shi Y. Molecular mechanisms of caspase regulation during apoptosis. Nat Rev Mol Cell Biol 2004; 5: 897-907.

9. Borgese N, Fasana E. Targeting pathways of C-tail-anchored proteins. Biochim Biophys Acta 2011; 1808: 937-946.

10. Szegezdi E, Macdonald DC, Ni Chonghaile T, Gupta S, Samali A. Bcl-2 family on guard at the ER. Am J Physiol Cell Physiol 2009; 296: C941-C953.

11. Kaufmann T, Schlipf S, Sanz J, Neubert K, Stein R, Borner C. Characterization of the signal that directs $\mathrm{Bcl}-\mathrm{xL}$, but not $\mathrm{Bcl}-2$, to the mitochondrial outer membrane. J Cell Biol 2003; 160: 53-64.

12. Heath-Engel HM, Shore GC. Regulated targeting of Bax and Bak to intracellular membranes during apoptosis. Cell Death Differ 2006; 13: 1277-1280.

13. Heath-Engel HM, Chang NC, Shore GC. The endoplasmic reticulum in apoptosis and autophagy: role of the BCL-2 protein family. Oncogene 2008; 27: 6419-6433.

14. Rong YP, Aromolaran AS, Bultynck G, Zhong F, Li X, McColl K et al. Targeting Bcl-2-IP3 receptor interaction to reverse Bcl-2's inhibition of apoptotic calcium signals. Molecular Cell 2008; 31: 255-265.

15. Hacki J, Egger L, Monney L, Conus S, Rosse T, Fellay I et al. Apoptotic crosstalk between the endoplasmic reticulum and mitochondria controlled by Bcl-2. Oncogene 2000; 19: 2286-2295.

16. Hsu SY, Kaipia A, McGee E, Lomeli M, Hsueh AJ. Bok is a pro-apoptotic Bcl-2 protein with restricted expression in reproductive tissues and heterodimerizes with selective antiapoptotic Bcl-2 family members. Proc Natl Acad SciUSA 1997; 94: 12401-12406.

17. Inohara N, Ekhterae D, Garcia I, Carrio R, Merino J, Merry A et al. Mtd, a novel Bcl-2 family member activates apoptosis in the absence of heterodimerization with Bcl-2 and Bcl-xL. J Biol Chem 1998; 273: 8705-8710.
18. Gao S, Fu W, Durrenberger M, De Geyter C, Zhang H. Membrane translocation and oligomerization of hBok are triggered in response to apoptotic stimuli and Bnip3. Cell Mol Life Sci 2005; 62: 1015-1024.

19. Zhang H, Holzgreve W, De Geyter C. Evolutionarily conserved Bok proteins in the Bcl-2 family. FEBS Lett 2000; 480: 311-313.

20. Ke F, Voss A, Kerr JB, O'Reilly LA, Tai L, Echeverry N et al. BCL-2 family member BOK is widely expressed but its loss has only minimal impact in mice. Cell Death Differ 2012; 19: 915-925.

21. Bartholomeusz G, Wu Y, Ali Seyed M, Xia W, Kwong KY, Hortobagyi G et al. Nuclear translocation of the pro-apoptotic Bcl-2 family member Bok induces apoptosis. Mol Carcinog 2006; 45: 73-83.

22. Yakovlev AG, Di Giovanni S, Wang G, Liu W, Stoica B, Faden Al. BOK and NOXA are essential mediators of p53-dependent apoptosis. J Biol Chem 2004; 279: 28367-28374.

23. Hsu SY, Hsueh AJ. A splicing variant of the Bcl-2 member Bok with a truncated $\mathrm{BH} 3$ domain induces apoptosis but does not dimerize with antiapoptotic $\mathrm{Bcl}-2$ proteins in vitro. J Biol Chem 1998; 273: 30139-30146.

24. Rodriguez JM, Glozak MA, Ma Y, Cress WD. Bok, Bcl-2-related ovarian killer, is cell cycle-regulated and sensitizes to stress-induced apoptosis. J Biol Chem 2006; 281: 22729-22735.

25. Lindsten T, Ross AJ, King A, Zong W, Rathmell JC, Shiels HA et al. The combined functions of proapoptotic Bcl-2 family members Bak and Bax are essential for normal development of multiple tissues. Mol Cell 2000; 6: 1389-1399.

26. Rathmell JC, Lindsten T, Zong W-X, Cinalli RM, Thompson CB. Deficiency in Bak and Bax perturbs thymic selection and lymphoid homeostasis. Nat Immunol 2002; 3: 932-939.

27. Beroukhim R, Mermel CH, Porter D, Wei G, Raychaudhuri S, Donovan J et al. The landscape of somatic copy-number alteration across human cancers. Nature 2010; 463: 899-905.

28. Wei MC, Zong WX, Cheng EH, Lindsten T, Panoutsakopoulou V, Ross AJ et al. Proapoptotic $\mathrm{BAX}$ and $\mathrm{BAK}$ : a requisite gateway to mitochondrial dysfunction and death. Science 2001; 292: 727-730.

29. Vince JE, Wong WW, Khan N, Feltham R, Chau D, Ahmed AU et al. IAP antagonists target clAP1 to induce TNFalpha-dependent apoptosis. Cell 2007; 131: 682-693.

30. Dewson G, Kratina T, Sim HW, Puthalakath H, Adams JM, Colman PM et al. To trigger apoptosis, Bak exposes its $\mathrm{BH} 3$ domain and homodimerizes via $\mathrm{BH} 3$ :groove interactions. Mol Cell 2008; 30: 369-380.

31. Zha HB, Reed JC. Heterodimerization-independent functions of cell death regulatory proteins Bax and Bcl-2 in yeast and mammalian cells. J Biol Chem 1997; 272: 31482-31488.

32. Kuroda R, Ikenoue T, Honsho M, Tsujimoto S, Mitoma JY, Ito A. Charged amino acids at the carboxyl-terminal portions determine the intracellular locations of two isoforms of cytochrome b5. J Biol Chem 1998; 273: 31097-31102.

33. Horie C, Suzuki H, Sakaguchi M, Mihara K. Characterization of signal that directs c-tailanchored proteins to mammalian mitochondrial outer membrane. Mol Biol Cell 2002; 13: 1615-1625.

34. Lithgow T, van Driel R, Bertram JF, Strasser A. The protein product of the oncogene bcl-2 is a component of the nuclear envelope, the endoplasmic reticulum and the outer mitochondrial membrane. Cell Growth Differ 1994; 5: 411-417.

35. Gotow T, Shibata M, Kanamori S, Tokuno O, Ohsawa Y, Sato N et al. Selective localization of $\mathrm{Bcl}-2$ to the inner mitochondrial and smooth endoplasmic reticulum membranes in mammalian cells. Cell Death Differ 2000; 7: 666-674.

36. Lisauskas T, Matula P, Claas C, Reusing S, Wiemann S, Erfle H et al. Live-cell assays to identify regulators of ER-to-Golgi trafficking. Traffic 2012; 13: 416-432.

37. Scorrano L, Oakes SA, Opferman JT, Cheng EH, Sorcinelli MD, Pozzan T et al. BAX and BAK regulation of endoplasmic reticulum $\mathrm{Ca} 2+:$ a control point for apoptosis. Science 2003; 300: 135-139.

38. Zong WX, Li C, Hatzuvassiliou G, Lindsten T, Yu QC, Yuan J et al. Bax and Bak can localize to the endoplasmic reticulum to initiate apoptosis. J Cell Biol 2003; 162: 59-69.

39. Hetz $\mathrm{C}$. The unfolded protein response: controlling cell fate decisions under $\mathrm{ER}$ stress and beyond. Nat Rev Mol Cell Biol 2012; 13: 89-102.

40. Zhang $\mathrm{H}$, Huang $\mathrm{Q}, \mathrm{Ke} \mathrm{N}$, Matsuyama S, Hammock B, Godzik A et al. Drosophila pro-apoptotic Bcl-2/Bax homologue reveals evolutionary conservation of cell death mechanisms. J Biol Chem 2000; 275: 27303-27306.

41. Dewson G, Kratina T, Czabotar P, Day CL, Adams JM, Kluck RM. Bak activation for apoptosis involves oligomerization of dimers via their alpha6 helices. Mol Cell 2009; 36: 696-703.

42. Zha H, Reed JC. Hetereodimerization-independent functions of cell death regulatory proteins Bax and Bcl-2 in yeast and mammalian cells. J Biol Chem 1997; 272: 31482-31488.

43. He H, Lam M, McCormick TS, Distelhorst CW. Maintenance of calcium homeostasis in the endoplasmic reticulum by Bcl-2. J Cell Biol 1997; 138: 1219-1228.

44. Thomenius MJ, Wang NS, Reineks EZ, Wang Z, Distelhorst CW. Bcl-2 on the endoplasmic reticulum regulates Bax activity by binding to $\mathrm{BH} 3$ only proteins. J Biol Chem 2003; 278 : 6243-6250.

45. Hetz C, Bernasconi P, Fisher J, Lee AH, Bassik MC, Antonsson B et al. Proapoptotic BAX and BAK modulate the unfolded protein response by a direct interaction with IRE1alpha. Science 2006; 312: 572-576.

46. Rusinol AE, Cui $Z$, Chen MH, Vance JE. A unique mitochondria-associated membrane fraction from rat liver has a high capacity for lipid synthesis and contains 
pre-Golgi secretory proteins including nascent lipoproteins. J Biol Chem 1994; 269 27494-27502.

47. Puthalakath $\mathrm{H}$, O'Reilly LA, Gunn $\mathrm{P}$, Lee L, Kelly PN, Huntington ND et al. ER stress triggers apoptosis by activating BH3-only protein Bim. Cell 2007; 129: 1337-1349.

48. Ray JE, Garcia J, Jurisicova A, Caniggia I. Mtd/Bok takes a swing: proapoptotic Mtd/Bok regulates trophoblast cell proliferation during human placental development and in preeclampsia. Cell Death Differ 2009; 17: 846-859.

49. Egger L, Schneider J, Rheme C, Tapernoux M, Hacki J, Borner C. Serine proteases mediate apoptosis-like cell death and phagocytosis under caspase-inhibiting conditions. Cell Death Differ 2003; 10: 1188-1203.
50. Walter D, Schmich K, Vogel S, Pick R, Kaufmann T, Hochmuth FC et al. Switch from type II to I Fas/CD95 death signaling on in vitro culturing of primary hepatocytes. Hepatology 2008; 48: 1942-1953.

51. Rosner M, Hengstschlager M. Cytoplasmic and nuclear distribution of the protein complexes mTORC1 and mTORC2: rapamycin triggers dephosphorylation and delocalization of the mTORC2 components rictor and sin1. Hum Mol Genet 2008; 17 : 2934-2948.

52. Grabenbauer M, Geerts WJ, Fernadez-Rodriguez J, Hoenger A, Koster AJ, Nilsson T. Correlative microscopy and electron tomography of GFP through photooxidation. Nat Methods 2005; 2: 857-862.

Supplementary Information accompanies the paper on Cell Death and Differentiation website (http://www.nature.com/cdd) 